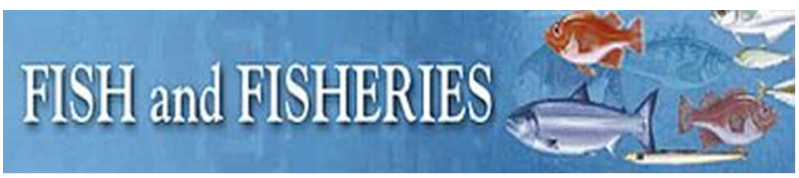

\title{
Modeling climate change impacts on marine fish populations: Process-based integration of ocean warming, acidification and other environmental drivers
}

\begin{tabular}{|c|c|}
\hline Journal: & Fish and Fisheries \\
\hline Manuscript ID & FaF-15-May-OA-080.R2 \\
\hline Wiley - Manuscript type: & Original Article \\
\hline Date Submitted by the Author: & $\mathrm{n} / \mathrm{a}$ \\
\hline Complete List of Authors: & $\begin{array}{l}\text { Koenigstein, Stefan; University of Bremen, Sustainabilty Research Center } \\
\text { (artec); Alfred Wegener Institute Helmholtz Centre for Polar and Marine } \\
\text { Research, Integrative Ecophysiology Section } \\
\text { Mark, Felix; Alfred Wegener Institute Helmholtz Centre for Polar and } \\
\text { Marine Research, Integrative Ecophysiology Section } \\
\text { Gößling-Reisemann, Stefan; University of Bremen, Sustainability Research } \\
\text { Center (artec); University of Bremen, Department of Resilient Energy } \\
\text { Systems } \\
\text { Reuter, Hauke; Leibniz Center for Tropical Marine Ecology, Dept. of } \\
\text { Theoretical Ecology and Modelling; University of Bremen, Faculty of Biology } \\
\text { and Chemistry } \\
\text { Pörtner, Hans-Otto; Alfred Wegener Institute Helmholtz Centre for Polar } \\
\text { and Marine Research, Integrative Ecophysiology Section; University of } \\
\text { Bremen, Faculty of Biology and Chemistry }\end{array}$ \\
\hline Key terms: & $\begin{array}{l}\text { ecosystem modeling, environmental drivers, climate change, ocean } \\
\text { acidification, fish ecophysiology, process understanding }\end{array}$ \\
\hline Abstract: & $\begin{array}{l}\text { Global climate change affects marine fish through drivers such as warming, } \\
\text { acidification and oxygen depletion, causing changes in marine ecosystems } \\
\text { and socio-economic impacts. Experimental and observational results inform } \\
\text { about anticipated effects of different drivers, but linking between these } \\
\text { results and ecosystem level changes requires quantitative integration of } \\
\text { physiological and ecological processes into models to advance research and } \\
\text { inform management. } \\
\text { We give an overview of important physiological and ecological processes } \\
\text { affected by environmental drivers. We then provide a review of available } \\
\text { modelling approaches for marine fish, analysing their capacities for } \\
\text { process-based integration of environmental drivers. Building on this, we } \\
\text { propose approaches to advance important research questions. } \\
\text { Examples of integration of environmental drivers exist for each model } \\
\text { class. Recent extensions of modelling frameworks have a greater potential } \\
\text { for including detailed mechanisms to advance model projections. } \\
\text { Experimental results on energy allocation, behaviour and physiological } \\
\text { limitations will advance the understanding of organism-level trade-offs and }\end{array}$ \\
\hline
\end{tabular}


Page 1 of 93

Fish and Fisheries

thresholds in response to multiple drivers. More explicit representation of life cycles and biological traits can improve description of population dynamics and adaptation, and data on food web topology and feeding interactions help detail the conditions for possible regime shifts. Identification of relevant processes will benefit the coupling of different models to investigate spatial-temporal changes in stock productivity and responses of social-ecological systems.

Thus, a more process-informed foundation for models will promote the integration of experimental and observational results and increase the potential for model-based extrapolations into a future under changing environmental conditions.

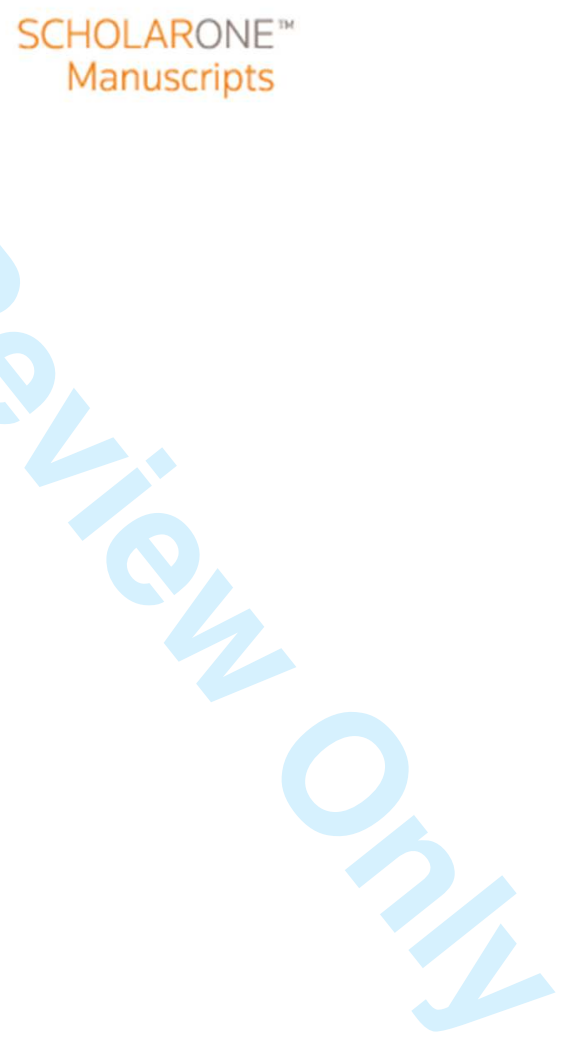


1 Modelling climate change impacts on marine fish populations: Process-based

2 integration of ocean warming, acidification, and other environmental drivers

3 Alternative 1: Modelling climate change impacts on marine fish populations:

4 Process-based integration of environmental drivers

5 Alternative 2: Integration of process-based understanding into ecological models for

6 marine fish

7 Stefan Koenigstein ${ }^{1,2}$, Felix C. Mark², Stefan Gößling-Reisemann ${ }^{1,3}$, Hauke Reuter ${ }^{4,5}$, Hans-

8 Otto Poertner 2,5

$9 \quad{ }^{1}$ Sustainability Research Center (artec), University of Bremen

$10{ }^{2}$ Integrative Ecophysiology section, Alfred Wegener Institute (AWI) Helmholtz Centre for

11 Polar and Marine Research

$12{ }^{3}$ Department of Resilient Energy Systems, University of Bremen

$13{ }^{4}$ Dept. of Theoretical Ecology and Modelling, Leibniz Center for Tropical Marine Ecology

$14{ }^{5}$ Faculty of Biology and Chemistry, University of Bremen

15 Correspondence:

16 Stefan Koenigstein, University of Bremen, artec Sustainability Research Center, Enrique-

17 Schmidt-Str. 7, D-28359 Bremen, Germany.

18 Tel. +49-421-64894, E-mail: koenigstein@uni-bremen.de

19 running title: Modelling environmental drivers for fish 


\section{Abstract}

21 Global climate change affects marine fish through drivers such as warming, acidification

22 and oxygen depletion, causing changes in marine ecosystems and socio-economic impacts.

23 Experimental and observational results inform about anticipated effects of different

24 drivers, but linking between these results and ecosystem level changes requires

25 quantitative integration of physiological and ecological processes into models to advance

26 research and inform management.

27 We give an overview of important physiological and ecological processes affected by 28 environmental drivers. We then provide a review of available modelling approaches for

29 marine fish, analysing their capacities for process-based integration of environmental

30 drivers. Building on this, we propose approaches to advance important research questions.

31 Examples of integration of environmental drivers exist for each model class. Recent

32 extensions of modelling frameworks have a greater potential for including detailed

33 mechanisms to advance model projections. Experimental results on energy allocation,

34 behaviour and physiological limitations will advance the understanding of organism-level

35 trade-offs and thresholds in response to multiple drivers. More explicit representation of

36 life cycles and biological traits can improve description of population dynamics and

37 adaptation, and data on food web topology and feeding interactions help detail the

38 conditions for possible regime shifts. Identification of relevant processes will benefit the

39 coupling of different models to investigate spatial-temporal changes in stock productivity 40 and responses of social-ecological systems. 
41 Thus, a more process-informed foundation for models will promote the integration of

42 experimental and observational results and increase the potential for model-based

43 extrapolations into a future under changing environmental conditions.

44 Key words:

45 ecosystem modelling, environmental drivers, climate change, ocean acidification, fish

46 ecophysiology, process understanding

47 Table of content:

48 Introduction

49 From drivers to processes: Physiological and ecological processes affected by environmental

50 drivers

51 Organism level processes, and suborganismal processes interacting on the individual level

52 Population level processes: recruitment, reproduction, population adaptation

53 Community level processes: predation, competition, mutualism \& facilitation

54 Spatial ecosystem level processes: migration, dispersal, habitat availability

55 From processes to models: Modelling approaches and their capacity for process-based

56 integration of environmental drivers

57 Single-species population dynamic models

58 Multi-species population dynamic models

59 Trophodynamic \& mass-balance models

60 Species Distribution Models (SDMs) 
61 Trait-based \& size-spectrum models

62 Individual-based models (IBMs)

63 Bioenergetic models

64 Coupled and end-to-end models

65 From models to understanding and projections: Model choices and challenges for addressing 66 questions of environmental change

67 Question 1: What is the individual response and tolerance of fish to multiple changing 68 environmental drivers?

69 Question 2: How will climate change affect the population dynamics of fish stocks and what is

70 their capacity for adaptation?

71 Question 3: Will marine food webs be resilient to climate change, or can regime shifts occur?

72 Question 4: How will the spatial distribution and range of stocks change?

73 Question 5: What will be the socio-economic impacts and the implications for management of

74 changing marine ecosystems?

75 Conclusions

76 Acknowledgements

77 References 


\section{Introduction}

79 The productivity of marine fish stocks is influenced by a multitude of environmental

80 factors. In the near future, many stocks will be increasingly affected by climate change

81 including global ocean warming, ocean acidification, oxygen loss and other long-term and

82 more regional environmental changes such as salinity, nutrient redistribution or

83 eutrophication and pollution (Roessig et al., 2005, Cochrane et al., 2009, Hollowed et al.,

84 2013, Pörtner et al., 2014). Environmental drivers affect marine ecosystems, marine

85 organisms and fish stocks through direct impacts on individual physiology and life history,

86 and/or indirectly via changes in primary productivity or ecological (mainly food web)

87 interactions, spatial configuration of habitats, or planktonic larval transport (Doney et al.,

88 2012, Metcalfe et al., 2012).

89 Responses to these environmental drivers, e.g. through changes in productivity and spatial 90 distribution will co-determine the future development of fish stocks and fisheries (Perry et

91 al., 2005, Lehodey et al., 2006). For instance, periodic changes between anchovy and

92 sardine regimes in the North Pacific can be explained by different optimum growth

93 temperatures (Takasuka et al., 2007, Lindegren and Checkley, 2013), and warming

94 temperatures have contributed to recently high stock levels in Barents Sea cod (Ottersen et

95 al., 2006, Kjesbu et al., 2014). In tropical and upwelling areas, and due to the general

96 warming trend, low oxygen availability can set physiological limits to fish stocks (Ekau et

97 al., 2010, Stramma et al., 2010). Across marine ecosystems, ocean acidification has emerged 
98

100

101

102

103

104 105

106

108

109

110

111

114 115

116

as an additional threat for marine fish populations e.g. through impacts on larval behaviour and associated mortality as seen in coral reef fish (Munday et al., 2010).

Climate change impacts different hierarchical levels of biological organization, from individual physiology and population level changes to community and ecosystem shifts (Le Quesne and Pinnegar, 2012). Many of the direct effects on organisms can only be observed and investigated at the cellular or individual level, and to assess their overall stock effects, they have to be scaled up to population and community level, thus integrating processes on the different levels (Rijnsdorp et al., 2009, Pörtner and Peck, 2010). Physiological processes link the physical environment to individual-level responses and thus help to gain principal mechanism-based understanding of climate change impacts on populations and ecosystems (Pörtner and Farrell, 2008, Denny and Helmuth, 2009, Chown et al., 2010).

To anticipate climate change effects in marine ecosystems, ecological simulation models allow for the inclusion of processes on different hierarchical levels of biological organization, and an analysis of their mutual feedbacks. Models may integrate the impacts of multiple drivers on fish from the physiological to the community and ecosystem levels, and to analyse stock dynamics under different scenarios of environmental change. To improve model projections and test hypotheses about environmental determinants for fish stocks, it is necessary to investigate mechanisms underlying stock dynamics and distribution (Hollowed et al., 2009, Hare, 2014). As empirical or statistical descriptions are based on the observed range of the combined underlying factors, historical data and identified patterns for fish stocks may fail to resolve uncertainties of projections if the 
119 underlying processes, e.g. life history, energetics, and recruitment patterns, change and 120 causalities are not understood (Mangel and Levin, 2005).

121 A more mechanistic formulation of models could be based on the explicit consideration of 122 physiological and ecological processes that determine observed phenomena (Baskett, 123 2012, Metcalfe et al., 2012). This could increase the projection capacities of models under

124 new combinations of environmental drivers (Jørgensen et al., 2012, Russell et al., 2012).

125 These models could make better use of results from advanced experiments on multiple 126 drivers (Denman et al., 2011, Dupont and Pörtner, 2013) and be tested with observations 127 on stock dynamics in already changing environments, facilitating development of early128 warning signs for productivity changes in fish stocks (Brander, 2010). In the light of 129 recently increased efforts to establish ecosystem-based fisheries management approaches 130 and the growing importance of societal climate adaptation, an integration of knowledge 131 about ecological and physiological processes seems necessary more than ever before (Cury 132 et al., 2008, Miller et al., 2010, Persson et al., 2014).

133 Although models for use in climate change projections and ecosystem-based fisheries 134 management have been reviewed for general strengths and weaknesses (Keyl and Wolff, 135 2007, Plagányi, 2007, Stock et al., 2011, Hollowed et al., 2012) and some approaches for 136 better integration of physiological data and mechanistic concepts have been proposed 137 (Metcalfe et al., 2012, Persson et al., 2014), a systematic inspection of possible directions 138 for advancement is currently lacking. An up-to-date and comprehensive review of 139 modelling approaches for marine fish and options for direct integration of environmental 
140 effects therefore seems timely and may facilitate better interdisciplinary exchange and

141 well-coordinated progress in this fast-developing field.

142 In this article, we will provide an overview of potentially relevant physiological and

143 ecological processes to understand climate change impacts on fish stocks (section two). We

144 then review available modelling approaches and present examples for marine fish species,

145 analysing them for their potential and limitations to incorporate environmental impacts on

146 the identified processes (section three). In the closing section, we exemplify the challenges

147 and potential for the advancement of models by addressing five key questions in regard to

148 climate change impacts on marine fish, in the context of changes in their ecosystems and in

149 human resource uses.

150 From drivers to processes: Physiological and ecological processes affected by environmental

151 drivers

152 Physiological processes act from the cellular to the organism level, and can be used to 153 explain direct effects of environmental drivers and individual tolerance towards changes.

154 They affect and are affected by higher levels of biological organization, such as the 155 population or community and ecosystem interactions, where ecological processes can 156 serve to extrapolate the impacts of climate change, ocean acidification and other drivers 157 (Pörtner and Peck, 2010, Monaco and Helmuth, 2011, Gaylord et al., 2015). As a framework 158 for structuring our analysis of modelling approaches, we will consider physiological and 159 ecological key processes, organized by the level of biological organization on which they act 
160 primarily (Fig. 1). This is intended to help the reader identify potentially relevant processes

161 as the basis for choosing an appropriate model.

162

163

164 Environmental drivers can affect a range of processes at the organismal level, and

165 individual tolerance of fish is co-defined by suborganismal (i.e. tissue and cellular) level

166 capacities and processes (cf. Fig. 1). Basic organism processes such as routine activity,

167 growth and reproduction are sustained only in a limited range of temperatures, indicating

168 thermal specialization. Through its effects on metabolic processes in ectothermic animals,

169 temperature modifies development and growth rates. Elevated temperatures entail

170 increased metabolic rates and energy turnover (Clarke and Johnston, 1999). However,

171 when a critical temperature is reached, aerobic physiological performance fails to increase

172 further or is even reduced, due to limited oxygen availability and capacities of respiratory,

173 ventilatory, and cardiovascular systems. Sustained performance relies on aerobically

174 produced metabolic energy, thus oxygen availability sets general limits to fish metabolism

175 and growth (Pauly, 2010). Organismal capacities vary between behavioural types and

176 habitat adaptations, e.g. active pelagic swimmers vs. benthic ambush predators,

177 eurythermal vs. stenothermal habitats (Pörtner et al., 2004). Individual fish behaviour thus

178 has consequences for population, community and ecosystem processes, and behavioural

179 adaptation may also buffer impacts of environmental drivers on individuals and

180 populations (Mittelbach et al., 2014). 
181 Limitations to an animal's performance and tolerance to unfavourable environmental 182 conditions will eventually become visible at the whole animal level, but are co-defined at 183 the cellular level. While temperature may be the most important factor in setting these 184 limits (Pörtner and Peck, 2010), further environmental factors such as ocean acidification 185 or hypoxia (low $\mathrm{O}_{2}$ levels) can modify aerobic capacity and temperature limits (Pörtner, 186 2010, 2012). Hypoxia has for instance been shown to reduce food uptake and limit 187 metabolic and growth rates and development of early life stages in fish (Ekau et al., 2010).

188 More recently, ocean acidification (declining oceanic $\mathrm{pH}$ and elevated $\mathrm{CO}_{2}$ levels) has been 189 identified as an additional driver, underscoring the necessity to integrate physiological 190 responses and experimental results on interactions among drivers into models and 191 projections (Fabry et al., 2008, Riebesell and Gattuso, 2015).

192 High seawater $\mathrm{CO}_{2}$ levels increase $\mathrm{CO}_{2}$ diffusion into the bloodstream of marine fish, which 193 is generally compensated within hours to days by an active accumulation of bicarbonate $194\left(\mathrm{HCO}_{3}^{-}\right)$to maintain the extracellular $\mathrm{pH}$ required for efficient cellular functioning (e.g. 195 Heisler, 1984, Brauner and Baker, 2009, Melzner et al., 2009b). The increased energy 196 demand of compensatory metabolic processes such as acid-base regulation (Deigweiher et 197 al., 2008, Melzner et al., 2009a) can entail shifts in the animal's energy budget, and lead to 198 acclimatory responses in various physiological processes. Consequently, ocean acidification 199 will act in addition to, or synergistically with, ocean warming, leading to decreased upper 200 critical temperatures (Pörtner and Peck, 2010). Recent studies have demonstrated a 201 considerable chronic impact of ocean acidification, e.g. on cellular metabolism (Strobel et 202 al., 2012, Strobel et al., 2013), metabolic rate (Michaelidis et al., 2007, Enzor et al., 2013), 203 respiratory performance (Couturier et al., 2013) and aerobic scope (Rummer et al., 2013). 
204 Thus, consideration of the physiological processes involved in individual responses can 205 serve to integrate the effects of multiple drivers (increasing temperature, acidification, 206 hypoxia) and to assess the combined effect on the organism and the energetic cost of 207 individual acclimation.

\section{Population level processes: recruitment, reproduction, population adaptation}

209 Processes at the population level, such as recruitment, determine the dynamics of fish

210 stocks and can be strongly influenced by the physical environment (Rothschild et al., 1989,

211 Myers, 1998, Ottersen et al., 2013, Szuwalski et al., 2014). Increasing temperatures lead to

212 faster development of fish larval stages, earlier maturation at smaller sizes and reduced

213 per-capita fecundity, affecting population productivity (Rijnsdorp et al., 2009, Baudron et

214 al., 2014).

215 Embryos and larval stages do not yet express the fully developed capacities for acid-base 216 regulation of juvenile and adult fish. Thus, additional stressors such as ocean acidification,

217 hypoxia or pollution can lead to increased mortality and impaired growth performance

218 (Franke and Clemmesen, 2011, Baumann et al., 2012, Frommel et al., 2012, Nikinmaa,

219 2013). Increased temperature and ocean acidification can also affect reproductive output

220 and gamete survival, impacting reproduction of the population (Inaba et al., 2003, Frommel

221 et al., 2010, Miller et al., 2015). Thus, egg and larval stages are potential bottlenecks in life

222 history and in adaptation of fish to multiple environmental drivers (Melzner et al., 2009b,

223 Rijnsdorp et al., 2009). 
224 Whether adaptation of fish populations can keep pace with future changes in

225 environmental conditions is an important open research question (Rijnsdorp et al., 2009).

226 Population adaptation can happen within the range of phenotypic plasticity, e.g. through

227 behavioural adaptation, developmental and trans-generational acclimation (Crozier and

228 Hutchings, 2014), or by evolution of adaptive genetic divergence (Nielsen et al., 2009,

229 Reusch, 2014). While genomic markers have been linked to ecological differentiation e.g. in

230 Atlantic cod (Hemmer-Hansen et al., 2013), most available studies have found plastic

231 responses, and studies reporting trans-generational plasticity under conditions of climate

232 change are relatively scarce for large and long-lived fish species (Crozier and Hutchings,

233 2014, Munday, 2014). However, some laboratory and in situ experiments demonstrate that

234 heritable effects can significantly enhance tolerance to environmental drivers and involve

235 metabolic readjustments (Donelson and Munday, 2012, Miller et al., 2012, Shama et al.,

236 2014). Effects of climate change at the population level may also act synergistically with

237 impacts of human exploitation, as fishing pressure can lead to a reduction in size at

238 maturation (Law, 2000, Jørgensen et al., 2007) and to a higher sensitivity towards

239 environmental fluctuations in exploited stocks (Perry et al., 2010).

240 Community level processes: predation, competition, mutualism \& facilitation

241 Direct environmental effects on fish are influenced by species interactions in the food web,

242 and can lead to indirect effects on other species (e.g. Link et al., 2009, Engelhard et al.,

243 2014, Bogstad et al., 2015). The response of a marine ecosystem to changes of one stock

244 depends on the type of trophic control, i.e. bottom-up or top-down (Frank et al., 2006), and

245 the characteristics of predator-prey interactions are a primary determinant of marine 
246 community resilience (Hunsicker et al., 2011). Cascading effects triggered by direct impacts

247 on one element of the food web may be especially relevant in top-down controlled systems

248 (Frank et al., 2006), can lead to regime or phase shifts, and therefore have to be considered

249 when discussing effects of climate change (Mangel and Levin, 2005, Link et al., 2009).

250 Changes in prey biomass and composition can influence the energy uptake for fish due to 251 different energy content or size of food particles (Beaugrand et al., 2003, Beaugrand and 252 Kirby, 2010). Regional changes in zooplankton communities are correlated to rising water 253 temperatures and may facilitate range shifts of fish stocks, which follow the occurrence of 254 their preferred prey (Brander, 2010, Dalpadado et al., 2012). Calcifying zooplankton 255 species, e.g. pteropods, may be vulnerable to ocean acidification and warming (Lischka and 256 Riebesell, 2012). Non-calcifying zooplankton, such as copepods, have displayed a reduced 257 overall energy content under warming and acidification (Hildebrandt et al., 2014), and may 258 also be impacted indirectly through reduced food quality of phytoplankton (Rossoll et al., 259 2012).

260 Changes in trophic interactions and energy transfer will be modulated by individual animal 261 feeding behaviour. Behaviour and sensory systems of fish can be influenced by elevated $262 \mathrm{CO}_{2}$ levels putatively through interaction with neuronal receptors (Briffa et al., 2012, 263 Nilsson et al., 2012, Hamilton et al., 2014). Effects have been shown to occur in all life 264 stages in laboratory and field experiments mostly of tropical reef fish (but see Jutfelt et al., 265 2013, Jutfelt and Hedgarde, 2013) and include impaired olfactory, visual and hearing 266 abilities (Simpson et al., 2011, Leduc et al., 2013, Chung et al., 2014), reduced capacities for 267 learning, homing and decision-making (Devine et al., 2012, Ferrari et al., 2012), and 
268 reduced or delayed behavioural responses towards predators (Ferrari et al., 2011, Munday 269 et al., 2013a, Nagelkerken et al., 2015).

270 In sharks, warming and acidification can impair growth and hunting behaviour (Pistevos et 271 al., 2015).

272 Thus, changes in planktonic community composition and predator-prey interactions point

273 at probable changes in food composition for fish and in marine community dynamics. Other

274 interactions, such as mutualism, facilitation or parasitism, may also be affected by changed

275 occurrences and sensitivities of species, and influence the response at the community level.

\section{Spatial ecosystem level processes: migration, dispersal, habitat availability}

277 The spatial heterogeneity of marine habitats influences the range of environmental

278 conditions experienced by individuals, and interacts with population and community

279 processes (Ciannelli et al., 2008). Changes in distribution ranges of marine fish species

280 under climate change, are based on the spatial processes migration and dispersal, and on

281 the availability of suitable habitat (Roessig et al., 2005). For instance, vertical foraging

282 migrations or large-distance seasonal migrations can be linked to characteristic

283 temperature corridors (e.g. Kitagawa et al., 2000, Stensholt, 2001). Spatial structure and

284 distribution of stocks can be shaped by migratory behaviour and larval dispersal, as

285 governed by oceanic currents and bottom topography (e.g. Rindorf and Lewy, 2006,

286 Knutsen et al., 2007). Local impacts of climate change e.g. in spawning or nursery grounds

287 can thus disrupt spatial life cycles via recruitment success (Petitgas et al., 2012, Llopiz et 
288 al., 2014). Spatial structure of fish stocks also influences the response to harvesting 289 (Ciannelli et al., 2013).

290 Ocean warming may reduce dispersal distances and decrease population connectivity due 291 to faster larval development, and can lead to shifts in seasonal spawning timing (O'Connor 292 et al., 2007, Asch, 2015). Experimental and empirical data can elucidate these spatial293 temporal organism-habitat connections. Processes such as migration and recruitment can 294 in principle be described as a result of behavioural responses to the spatial environment, 295 governed by physiological capabilities and limitations (cf. Fiksen et al., 2007).

296 Observational and telemetry data can be used to inform about population movements 297 (Metcalfe et al., 2012), and genomic methods can reveal fine-scale population structuring 298 and local or regional adaptive differentiation in fish species (Nielsen et al., 2009).

\section{From processes to models: Modelling approaches and their capacity for process-based} integration of environmental drivers

In this section, the main types of models used to investigate marine fish are analysed for their capacity to incorporate the effects of environmental drivers on specific physiological and ecological processes. For clarity, we divide the models into seven categories: 1) singlespecies population dynamic models, 2) multi-species population dynamic models, 3) trophodynamic \& mass-balanced models, 4) species distribution models (SDMs), 5) traitbased \& size-spectrum models, 6) individual-based models (IBMs), and 7) bioenergetic models. These categories represent historical developments, but no definitive functional distinctions. Modelling approaches are under rapid development and continuously 
309 incorporating new possibilities, sometimes originating from other model classes. Finally,

310 we describe approaches and issues for the coupling of models and coupled end-to-end 311 models.

312 We aim to explain the underlying concepts, and review recent applications and extensions 313 with regard to the incorporation of environmental drivers, to give a guideline in the choice

314 of a suitable modelling approach. Furthermore, we present relevant freely available 315 software packages, to encourage the reader to try out models and gain a better

316 understanding of the underlying assumptions.

\section{Single-species population dynamic models}

318 Single-species population dynamic models descend from models used for traditional 319 fisheries stock assessment (Ricker, 1954, Beverton and Holt, 1957). These models rely on 320 catch and survey data to estimate fish stock size, and simulate stock dynamics based on 321 estimated population-level parameters like biomass, growth rate, recruitment, fishing and 322 natural mortality (Hilborn, 2012). Extensions have divided stocks into age and/or size 323 classes that can possess varying mortalities and growth (Deriso et al., 1985, Fournier et al., 324 1990), and 'matrix population' models consider both factors e.g. by describing stages 325 within age classes (Caswell, 2001).

326 Organism: Stock models with both size- and age-structure can integrate adjustments of 327 size-dependent or age-dependent processes (e.g. growth, mortality, development as shift to 328 the next stage) based on environmental effects. The effects of temperature have been 329 incorporated by tuning the growth function, e.g. for climate-dependent variations in 
330 Atlantic cod stocks (Brander, 1995, Clark et al., 2003), and by adjusting natural mortality,

331 e.g. in an age-structured model for Pacific saury (Cololabis saira, Scomberesocidae; Tian et

332 al., 2004). Assumed effects of changes in temperature, salinity and hypoxia on growth,

333 mortality and reproduction have been integrated in a matrix projection model for Atlantic

334 croaker (Micropogonias undulatus, Sciaenidae; Diamond et al., 2013).

335 Population: Stock assessment models aggregate early life stages in an empirical stock-

336 recruitment relationship (Needle, 2001), which determines critical characteristics of the

337 produced stock dynamics (e.g. Cabral et al., 2013). Environmental drivers have been

338 incorporated into recruitment functions (Hollowed et al., 2009), e.g. as temperature effects

339 on North Sea and Baltic cod (Köster et al., 2001, Clark et al., 2003), on tropical rock lobster

340 (Panulirus ornatus, Palinuridae; Plaganyi et al., 2011) and on Baltic sprat (Sprattus sprattus,

341 Clupeidae; Voss et al., 2011). The influences of atmospheric oscillations and regional

342 oceanographic regimes on recruitment have been incorporated e.g. for Atlantic cod

343 (Brander and Mohn, 2004), Northern rock sole (Lepidopsetta polyxystra, Pleuronectidae;

344 Hollowed et al., 2009) and jackass morwong (Nemadactylus macropterus, Cheilodactylidae;

345 Wayte, 2013).

346 Simpler, non stage-structured 'surplus production' models have investigated stock

347 dynamics as driven by temperature regimes and climate oscillations (Rose, 2004, Holsman

348 et al., 2012). Matrix projection models can incorporate more process detail, integrating

349 reproduction and estimating recruitment from growth, maturation and cannibalism

350 processes, as applied for Atlantic cod (Frøysa et al., 2002, Andrews et al., 2006) and

351 Atlantic croaker (Diamond et al., 2013). 
352 Community: Food web interactions are not explicitly incorporated in single-species

353 assessment models (see 'multi-species population dynamic models'), but are indirectly

354 considered through model fitting to stock observations. Stock models could take into

355 account changes in community level processes via adjusting stock growth or an additional

356 mortality parameter.

357 Spatial consideration: Movement of stocks has been integrated through grid cells

358 connected by advection and diffusion e.g. for albacore (Thunnus alalunga, Scombridae;

359 Fournier et al., 1998) and for Atlantic cod (Andrews et al., 2006). By modelling the

360 dynamics of metapopulations with distinct sub-stocks, differences in population

361 parameters and more detailed spatial processes such as migration, spatially disaggregated

362 spawning, and larval diffusion can be incorporated (Goethel et al., 2011).

\section{Multi-species population dynamic models}

364 Multi-species population dynamic models originate from the extension of single-species 365 stock assessment models (Pope, 1979, Gislason, 1999, Lewy and Vinther, 2004). These 366 models use diet data to couple several species via their feeding interactions, whereby the 367 mortality rate of a stock is determined from its consumption by other species (Pope, 1991, 368 Magnússon, 1995, Rose and Sable, 2009). Selection of the included species can be based on 369 abundance, relevance from an economic or management perspective, or because of key 370 interactions with the target species (Rindorf et al., 2013, Plaganyi et al., 2014b). Models

371 include up to six species and often aim to evaluate interdependent fluctuations of fish 372 stocks in response to environmental changes (e.g. Bogstad et al., 1997, Livingston, 2000). 
373 Organism: Due to an underlying structure equivalent to single-species population dynamic

374 models, multi-species models have essentially the same capacities and limitations for

375 integrating organism-level processes. The explicit consideration of species interactions

376 may allow a more realistic parameterization e.g. of natural mortality and growth

377 (Hollowed, 2000).

378 Population: Restrictions apply as for single species stock models. However, multi-species

379 models can include impacts of predation by other species on early life stages, as

380 demonstrated e.g. for Atlantic cod and interacting species (Lewy and Vinther, 2004,

381 Lindstrøm et al., 2009, Speirs et al., 2010). This would in principle allow for integration of

382 food-web mediated environmental effects on recruitment success.

383 Community: Multi-species models incorporate predation and competition processes

384 among the included species, with a moderate number of species assumed to be sufficient to

385 describe regional food web dynamics (Rindorf et al., 2013). The predation process is

386 formulated as a statistical 'functional response' between predator consumption and prey

387 abundance (Holling type functions; Holling, 1959), where prey suitability is usually based

388 on data from stomach content analysis (Magnússon, 1995). Environmental influence on the

389 predation process has been incorporated by dynamically modelling stomach content and

390 the impact of temperature on evacuation rates to represent metabolic activity, in a study

391 with Atlantic menhaden (Brevoortia tyrannus, Clupeidae) and its predators (Garrison et al.,

392 2010).

393 Spatial consideration: Multi-species models can divide stock representations into several

394 regional areas to include connecting processes such as seasonal migration patterns and 
395 larval dispersal, as realized for the Barents Sea (Tjelmeland and Bogstad, 1998, Lindstrøm 396 et al., 2009).

\section{Trophodynamic \& mass-balance models}

398 Trophodynamic or mass-balance models (also termed whole system or aggregate system 399 models) build on the analysis of mass or energy flows in ecological networks (Polovina, 400 1984, Ulanowicz, 1985). Exchange of biomass as wet weight or energy equivalents is 401 modelled among functional groups or 'compartments' (usually species or ecologically 402 similar groups of species) in marine food webs. Available software packages include 403 Econetwrk (Ulanowicz, 2004), which focuses on network analysis, Ecotroph (Gascuel and 404 Pauly, 2009), which analyses biomass flow through trophic levels, and the multifunctional 405 and widely utilised Ecopath with Ecosim package (EwE; Christensen and Walters, 2004).

Organism: Effects of temperature, acidification and hypoxia on physiological performance

407 of organisms have been incorporated in Ecosim by forcing functional groups or by 408 adjusting their aggregate production, consumption or mortality values (e.g. Ainsworth et 409 al., 2011, Cornwall and Eddy, 2015). The spatial EwE extension Ecospace (Walters et al., 410 1999) permits specifying habitat quality based on various environmental factors, which 411 then determines foraging capacity (Christensen et al., 2014a), and can divide life stages into 412 smaller packages to approach 'individual-based' functionality (Walters et al., 2010).

413 Population: The ,multi-stanza' feature in EwE facilitates the representation of life stages to 414 describe recruitment (Christensen and Walters, 2004, Walters et al., 2010), but 415 reproduction is not explicitly represented. As the underlying parameters are on functional 
416 group level, the analysis of plasticity and adaptation of populations is limited (Christensen

417 and Walters, 2004).

418 Community: Energy flow over trophic levels can inform about general ecosystem

419 characteristics and functioning (e.g. Link et al., 2008, Gascuel et al., 2011). The

420 differentiation of represented compartments (species or functional groups) can be adjusted

421 to optimize between food web resolution and data availability and reliability (Prato et al.,

422 2014), informed by general ecological knowledge and sensitivity analyses (Link, 2010,

423 Lassalle et al., 2014).

424 Predation is represented by a functional response depending on predator and prey

425 biomasses (Christensen and Walters, 2004). In principle, vulnerability settings for each

426 compartment provide an aggregate measure to integrate e.g. risk-sensitive foraging or

427 predation behaviour (Ahrens et al., 2012). Via forcing functions, consumption and

428 vulnerability parameters, or zooplankton groups and primary production can be adjusted

429 to represent impacts of climate change on feeding interactions or food availability (e.g.

430 Shannon et al., 2004, Field et al., 2006, Araújo and Bundy, 2012).

431 Spatial consideration: The Ecospace module of EwE can represent spatial-temporal

432 distribution of biomass, including probability functions of movement (Walters et al., 2010).

433 Habitat suitability, seasonal migrations and larval dispersal have been integrated e.g. for

434 areas in the Mediterranean (Libralato and Solidoro, 2009, Fouzai et al., 2012). Two recently

435 added features enable dynamic spatial-temporal environmental data input (Steenbeek et

436 al., 2013a) and more detailed integration of variable habitat suitability factors (Christensen

437 et al., 2014a). 


\section{Species Distribution Models (SDMs)}

439 Species Distribution Models (SDMs, also termed niche-based models, climate envelope 440 models, or predictive habitat distribution models) link observed geographical species

441 distributions to environmental parameters, classically through regression analysis (Guisan 442 and Zimmermann, 2000, Elith and Leathwick, 2009). Besides a wealth of applications in the 443 terrestrial realm, SDMs are increasingly used for projecting future distributions of marine 444 fish stocks from regional projections of environmental factors (Cheung et al., 2008, Cheung 445 et al., 2009, Lenoir et al., 2010). Dedicated SDM software platforms enable the application 446 and comparison of different algorithms (e.g. Thuiller et al., 2009).

447 Organism: Organism level effects of environmental drivers can readily be incorporated 448 into SDMs as performance curves dependent on physical factors. To integrate multiple 449 environmental variables, different suitability factors can be multiplied (e.g. Kaschner et al., 450 2006). Aerobic scope has been used to integrate effects of temperature, oxygen, $\mathrm{pH}$ and 451 food energy into the population growth function for marine fish stocks (Cheung et al., 452 2011).

453 SDMs which aim to increase detail by including functional relationships between physical 454 variables and species performance, e.g. thermodynamic energy transfer principles, have 455 been termed mechanistic SDMs or mechanistic niche models (Dormann, 2007, Kearney and 456 Porter, 2009). Under changing environmental conditions, increased care has to be taken in 457 the choice of environmental variables, species-specific data, and applied algorithms to 458 supply ecologically meaningful and robust projections (Araújo and Guisan, 2006, Heikkinen 459 et al., 2006, Austin, 2007). 
460 Population: A logistic population growth model incorporates temperature effects on

461 population carrying capacity to model the global distribution of fish species (Cheung et al.,

462 2008). As environmental correlations are usually based on the occurrence of adults, it is

463 difficult to include ontogenetic shifts in environmental tolerance or preference in different

464 life stages (Robinson et al., 2011), but more detailed, stage-structured representations of

465 population processes have been achieved in terrestrial models (e.g. Fordham et al., 2013).

466 Community: The incorporation of community shifts under climate change represents a

467 challenge for SDMs, as species interactions are only implicitly included in the empirically

468 based response function. Depending on the scale of projections, changes in species

469 interactions may significantly influence the performance of SDMs (Araújo and Rozenfeld,

470 2014). Mechanistic SDMs aim to exclude biotic interactions from the response function and

471 consider them separately (Guisan and Thuiller, 2005) to take into account differential

472 preferences of prey and predator for environmental factors (Robinson et al., 2011),

473 An SDM for the North Atlantic has been extended with community size-spectra to represent

474 competition between species as a division of available food energy (Fernandes et al., 2013).

475 For the Mediterranean Sea, a niche model has been coupled to a trophic network model to

476 derive temperature-induced shifts in food webs (Albouy et al., 2014).

477 Spatial consideration: SDMs can provide high spatial resolution, but correlations are

478 often limited by the availability of species occurrence data. Larval dispersal, adult

479 migrations, habitat availability and regional primary production changes have been

480 included into projections of worldwide distribution changes of marine fish (Cheung et al.,

481 2009, Cheung et al., 2010). Seasonal migrations and other spatio-temporal processes 
482 governed by factors other than current environmental parameters (e.g. genetic) are more

483 difficult to include (Robinson et al., 2011), but have been included e.g. in a habitat

484 prediction model for southern Bluefin tuna (Thunnus maccoyii, Scombridae) under

485 changing oceanographic conditions (Hartog et al., 2011).

\section{Trait-based \& size-spectrum models}

487 Trait-based models constitute a relatively new approach, focusing on the description of

488 individual characteristics and processes (traits), e.g. size, morphology or weight, which are 489 defined to govern performance of organisms in a specific environment (Chown, 2012).

490 These traits can be used together with metabolic scaling and predation rules to describe

491 life histories and interactions (Brown et al., 2004, Andersen and Beyer, 2006) and to

492 construct community size-spectrum models for fish (Benoit and Rochet, 2004, Pope et al.,

493 2006). A multi-species size spectrum modelling package, is available with an example

494 parameterized for the North Sea (Scott et al., 2014).

495 Organism: Trait-based models can incorporate considerable detail on organism-level

496 processes such as growth, foraging, reproduction and basal metabolism, modelling

497 organismal trade-offs via energy allocation (Jørgensen and Fiksen, 2006). For Atlantic cod

498 larvae, optimal vertical migration and life history strategies have been derived from

499 responses to the environmental variables food, temperature and light (Kristiansen et al.,

500 2009, Fiksen and Jorgensen, 2011). Recently, individual energy and oxygen budgets have

501 been used to derive changes in growth, mortality and reproduction rates under ocean

502 warming and project impacts on population characteristics and optimal behavioural and

503 life history strategies (Holt and Jørgensen, 2014, Holt and Jørgensen, 2015). 
504 Population: Trait-based models have high potential to describe processes shaping 505 population dynamics, such as reproduction and recruitment, by basing them on individual 506 life histories. These can be resolved for size, growth and maturation (e.g. Hartvig et al., 507 2011, Holt and Jørgensen, 2014). However, trait-based models usually include an empirical 508 stock-recruitment relationship to determine recruitment and represent closure of life 509 cycles (Jacobsen et al., 2014). Adaptation of fish populations to size-selective drivers (e.g.

510 fisheries exploitation) can be quantified based on changes of individual growth, 511 reproduction and mortality processes (Andersen and Brander, 2009). Eco-genetic or 512 adaptive dynamics models investigate plasticity and evolutionary rates within populations 513 (Dunlop et al., 2009).

514 Community: In size spectrum models, community interactions and food webs are usually 515 constructed bottom-up, based on the realized interactions as governed by the integrated 516 traits, e.g. 'size at maturation' (e.g. Jennings and Brander, 2010, Hartvig et al., 2011). Simple 517 size spectrum models can investigate community shifts under temperature effects on 518 growth (Pope et al., 2009). Behavioural, energy allocation and foraging processes can 519 connect individual processes in more detail (Andersen and Beyer, 2013), and functional 520 separation in interactions can be integrated by using coupled size spectra, as exemplified 521 for pelagic predators and benthic detritivores (Blanchard et al., 2009).

522 Spatial consideration: Size spectrum models can use spatial input from oceanographic 523 and biogeochemical models to incorporate e.g. temperature effects on feeding and 524 mortality (Blanchard et al., 2012) and to simulate movement (Watson et al., 2014). 


\section{$525 \quad$ Individual-based models (IBMs)}

526 Individual-based models (also termed agent-based models) are a bottom-up modelling 527 approach, based on the simulation of individuals as separate entities. Their status is 528 determined by internal state variables and changed by interactions with other individuals 529 and the environment (e.g. foraging and predation), generating population and higher-level 530 system properties (Huston et al., 1988, Judson, 1994, Grimm, 1999). Various IBM 531 programming packages focus on agent-environment interactions (Railsback et al., 2006, 532 Arunachalam et al., 2008). More specialized software tools model environmental impacts 533 on the dispersal of planktonic fish larvae (Lett et al., 2008, e.g. Huebert and Peck, 2014).

534 Organism: IBMs for larval fish describe growth, development and mortality as dependent 535 on environmental parameters (Hinckley et al., 1996, Hermann et al., 2001, Gallego et al., 536 2007). Behavioural rules can link environmental factors (e.g. light, temperature, oxygen) to 537 metabolism, energy use, and predation risk (Fiksen et al., 2007). Energy allocation 538 principles can be used to describe connections and trade-offs among internal processes in 539 IBMs (Sibly et al., 2013). More detailed environmental and experimental data is needed for 540 further advances in larval IBMs (Lett et al., 2010, Peck and Hufnagl, 2012).

541 Population: IBMs allow for consideration of inter-individual variation in fish responses 542 and the resulting environmental selection (Van Winkle et al., 1993) and can thus be used to 543 investigate population adaptation to changing environmental drivers (e.g. Anderson et al.,

544 2013). While representing both detailed early life stages and closed life cycles of 545 populations produces considerable model complexity and computational demands, IBMs 546 can be used to integrate variation into more aggregate models (Rose et al., 2001). 
547 IBMs have been used to investigate early life stage dynamics, connectivity between stocks

548 and environmental impact on recruitment potential of marine fish (Mullon et al., 2002,

549 Miller, 2007, Hinrichsen et al., 2011). Demographic changes under climate change have

550 been investigated for Atlantic salmon (Salmo salar, Salmonidae; Piou and Prévost, 2012).

551 Community: IBMs are successful in detailing the predation of larval fish on zooplankton

552 based on spatial co-occurrence, the environment and behavioural processes, e.g.

553 investigating match-mismatch dynamics (Kristiansen et al., 2011). Thus, growth and

554 mortality can be described as emergent properties of individual interactions, providing the

555 predation functional response with ecological detail (Huse and Fiksen, 2010).

556 Changes in lower trophic levels can be integrated as 'prey fields' (aggregated prey densities

557 in a defined space) into larval models (Hermann et al., 2001, Daewel et al., 2008). Size-

558 governed predation processes have been resolved in a multi-species IBM for pelagic fish

559 communities (OSMOSE; Shin and Cury, 2001, 2004; for this and other multi-species IBMs,

560 see section on 'coupled and end-to-end models').

561 Spatial consideration: Biophysical IBMs can model impacts on larval dispersal, based on

562 output from three-dimensional oceanographic models, as realized e.g. for larvae of walleye

563 pollock (Theragra chalcogramma, Gadidae; Hermann et al., 2001), Southern African

564 anchovy (Engraulis capensis, Engraulidae; Mullon et al., 2002), Atlantic cod (Vikebo et al.,

565 2007, Heath et al., 2008) and Atlantic herring (Vikebo et al., 2010). A mechanism-based, not

566 species-explicit model has been used to investigate climate change impacts on adult fish

567 and mammal migrations (Anderson et al., 2013). 


\section{Bioenergetic models}

569 Bioenergetic models simulate the internal energy budget of organisms by using rules for 570 energy allocation. Metabolic processes such as feeding, respiration, growth and

571 reproduction are linked to external parameters, e.g. food and temperature, to determine 572 the organism's performance (Brown et al., 2004, Hartman and Kitchell, 2008). Classic

573 bioenergetic models have been applied to a variety of fish species (Hansen et al., 1993). In 574 Dynamic Energy Budget (DEB) models (Kooijman, 2000, van der Meer, 2006), individuals 575 are characterized by the state of different energy compartments such as structure, reserves 576 and reproduction (Lika and Kooijman, 2011, Nisbet et al., 2012). Energy budget

577 representations have also been integrated into other model types (see 'Organism' 578 subsections of 'Trait-based \& size-spectrum models', 'Individual-based models' and 579 'Coupled and end-to-end models' sections).

Organism: Energy budgets have been used to compare temperature-dependent organism

581 performances and sensitivities among different fish species (van der Veer et al., 2001,

582 Sousa et al., 2008, Freitas et al., 2010). While this provides the base for a mechanistic

583 understanding of diverging organism performances under climate change, further research

584 will be required to incorporate life history and behavioural detail, activity costs, and

585 seasonal and ontogenetic variations in energy allocation (Beauchamp et al., 2007, Sibly et

586 al., 2013) as well as the treatment of oxygen supply for metabolism (Pauly, 2010).

587 Population: Bioenergetic models have been scaled up to population level to determine 588 parameters such as biomass, consumption and growth of fish stocks, based on changes in 589 metabolic and feeding rates (Beauchamp et al., 2007, Perez-Rodriguez and Saborido-Rey, 
590 2012). To include more detail on population level processes, DEBs have been integrated 591 into matrix population models (e.g. Klanjscek et al., 2006) and energy allocation patterns 592 adapted to the life-history of the organism (Nisbet et al., 2012).

593 Spawning dynamics resulting from temperature and food effects on energy budgets have 594 been investigated for European anchovy (Pecquerie et al., 2009) and Atlantic Bluefin tuna 595 (Thunnus thynnus, Scombridae; Chapman et al., 2011).The integration of energy budget 596 models into IBMs allows more detailed upscaling of individual-level processes to 597 population level (Hölker and Breckling, 2005, Sibly et al., 2013), and for DEB-IBM 598 integration a software framework is available (Martin et al., 2011, Martin et al., 2013).

599 Community: Predator-prey interactions in bioenergetic IBMs determine energy transfer 600 between individuals, and can therefore include changes in prey composition or energy 601 content (Martin et al., 2011). Behavioural aspects of foraging are more difficult to include 602 (Beauchamp et al., 2007). Dynamic Energy Budgets have been used to derive thermal 603 ranges of fishes in the North Sea (Freitas et al., 2010), and can be integrated into size604 spectra models to investigate community dynamics (Maury and Poggiale, 2013).

605 Spatial consideration: A DEB model has been coupled to biogeochemical and lower 606 trophic level models to investigate the spatial distribution of North Atlantic flatfish species 607 (Teal et al., 2012). To investigate detailed spatial processes, bioenergetic models have been 608 integrated into size-structured models (e.g. Maury, 2010; see 'Coupled and end-to-end 609 models'), and can be incorporated into individual-based and species distribution models, 610 but data availability and the complexity of organismal plasticity and ontogenetic changes 611 may limit their up-scaling to the ecosystem level (Freitas et al., 2010). 


\section{Coupled and end-to-end models}

613 As each modelling approach has characteristic strengths and simplifications, coupling of

614 different ecological models increases the potential for explicit process integration (cf.

615 Reuter et al., 2010). A range of coupled models is available, and some consist of a complex 616 array of submodels, connecting ecosystem levels and scientific disciplines (Moloney et al.,

617 2011) to achieve an 'end-to-end' representation of climate change impacts, i.e. from

618 physical oceanographic changes via nutrient dynamics and planktonic lower trophic levels,

619 to fish stocks, other higher trophic levels and links to socio-economic dynamics (Travers et

620 al., 2007, Fulton, 2010, Rose et al., 2010). To link across these levels, models can profit from

621 detailing processes, e.g. related to energy allocation, feeding and behaviour (Nisbet et al.,

622 2000, Brown et al., 2004, Kearney et al., 2010, Persson et al., 2014). Note that recent

623 extensions and advances in end-to-end modelling are not all covered in the peer-reviewed

624 literature, and it is beyond the scope of this paper to provide more than a short overview of 625 these models.

626 Three conceptually related models integrate oceanographic models, simplified nutrient and

627 lower trophic level dynamics and bioenergetic models for certain pelagic fish species.

628 APECOSM (Apex Predators ECOSystem Model; Maury, 2010) and SEAPODYM (Spatial

629 Ecosystem And POpulations DYnamics Model; Lehodey et al., 2008) represent size-

630 structured predation and movement in different tuna and related species, and have been

631 used to investigate worldwide distribution shifts under climate change (Lefort et al., 2015,

632 Lehodey et al., 2015). NEMURO.FISH (North Pacific Ecosystem Model for Understanding

633 Regional Oceanography - For Including Saury and Herring) has been developed to 
634 investigate climate regime effects on Pacific herring (Clupea pallasii pallasii, Clupeidae;

635 Megrey et al., 2007, Rose et al., 2008) and Pacific saury (Ito et al., 2004).

636 OSMOSE (Object-oriented Simulator of Marine ecOSystems Exploitation) is an IBM

637 representing multiple size classes and size-based interactions (Shin and Cury, 2004).

638 Recent OSMOSE versions have been used to investigate combined effects of climate change

639 and fisheries by coupling energy-dependent growth of early life stages to simple models of

640 lower trophic levels (Travers-Trolet et al., 2014). Based on environmental driving from the

641 NEMURO model, a recent multi-species IBM development for the California Current

642 simulates dynamics of Californian anchovy (Engraulis mordax, Engraulidae) and Pacific

643 sardine (Sardinops sagax caerulea, Clupeidae), linking to an agent-based fisheries model

644 (Fiechter et al., 2015, Rose et al., 2015).

645 Atlantis is a modular end-to-end model aimed at the evaluation of management strategies

646 (Fulton et al., 2004, Fulton et al., 2011). Fish stocks are age-structured, with average size

647 and condition tracked, and different types of functional responses can be used to describe

648 trophic interactions (Fulton, 2010, Kaplan et al., 2012). Effects of warming, acidification

649 and salinity changes have been integrated on represented processes such as growth,

650 reproduction, and movement (Griffith et al., 2012, Fulton and Gorton).

651 In principle, these comprehensive models possess a high potential for consideration of

652 multiple drivers for different species and at various levels of description. However, the

653 complexity of model structures causes a high work effort for estimating and analysing

654 empirical parameters, the consideration of scaling issues and the coupling of modules may 
655 be limited by calibration issues and the propagation of uncertainties (Fulton et al., 2003, 656 Rose, 2012, Voinov and Shugart, 2013, Evans et al., 2015).

657 As an alternative to the use of increasingly complex model structures, purposefully

658 simplified end-to-end models can quantify climate change impacts and provide

659 management advice. These have been termed 'models of intermediate complexity' (Hannah

660 et al., 2010) and can be related to or based on multi-species population dynamic models

661 (Plaganyi et al., 2014b). Recent examples have linked nutrient dynamics to fisheries

662 management for the North Sea and Baltic Sea (e.g. Heath, 2012, Radtke et al., 2013). Also,

663 Ecospace models (see 'Trophodynamic \& mass-balance models') can be driven with spatial-

664 temporal input from oceanographic models (Steenbeek et al., 2013) to investigate e.g.

665 interactions of hypoxia and fishing (de Mutsert et al., 2015). Lastly, in system dynamics

666 modeling, which aims at a simplified representation of social-ecological systems (Costanza

667 and Ruth, 1998), some examples for fish stocks in the Northwest Atlantic have

668 incorporated habitat conditions and management elements (Ruth and Lindholm, 1996,

669 Gottlieb, 1998).

670

671 questions of environmental change

672 Our compilation illustrates that modelling approaches have strongly diverging capacities to 673 incorporate physiological and ecological processes under scenarios of climate change

674 (Table 1). Most approaches concentrate on specific levels of organization and neglect

675 others, although in many cases recently added features have improved capacities. The best 
676 choice of model thus depends on the primary question of interest, the relevant processes

677 and the available data.

678 To exemplify relevant considerations when choosing or constructing a model, we consider

679 five basic research questions asked by the scientific community. Questions 1 to 3 relate to

680 advancing the fundamental understanding of biological responses of fishes to

681 environmental changes (individual tolerance, population adaptation and ecological regime

682 shifts). Questions 4 and 5 focus on projections of the future states of fish stocks (spatial

683 distribution and links to socio-economic developments). We evaluate the capabilities of the

684 presented model classes to treat these questions and suggest how these models may profit

685 from integrating more experimental results and empirical data. changing environmental drivers?

688

689

690

691

692

693

694

695

696
Laboratory experiments contribute primarily to this research question by investigating organism level processes that determine the effect of multiple and combined environmental drivers (increasing temperature, acidification, hypoxia) on individual performance. Research on the cumulative effects of stressors, life stage-specific sensitivities and trade-offs between physiological processes can build the foundation for explaining the capacity for and the limitations of individual plasticity.

Bioenergetic models can represent individual processes in greatest detail. To project effects on higher-level processes, energy budgets have been successfully integrated in individual-based, trait-based, size-spectrum, species distribution and end-to-end models. 
697 Individual-based and trait-based models on the individual level are most directly

698 parameterized with results from experiments, can consider inter-individual heterogeneity, 699 and facilitate a mechanistic understanding of the effects of different constraining or 700 enhancing factors on the performance of individuals. Due to detail richness and specificity 701 of model formulations, these models are often not easily transferable to other species. 702 When applied to multiple species and in a spatial ecosystem context, computational 703 demands can be high.

704 Species distribution models and Ecospace offer comparatively straightforward integration 705 of physiological performance curves into response functions to single and multiplicative 706 drivers. Due to the implicit assumptions regarding upscaling to higher levels of 707 organization, robustness and uncertainty of the applied response functions can be assessed 708 e.g. by using results on sub-lethal physiological responses, which can be provided by 709 laboratory experiments (Woodin et al., 2013). In single or multi-species population 710 dynamic and mass-balance models, experimental results can be used to adjust growth, 711 consumption and mortality of (age/size) stages or cohorts. As this kind of aggregated 712 integration of results does not account for individual variation in responses, robustness of 713 these representations should be assessed over the range of responses in regard to 714 interactions with other drivers and with processes on higher levels (such as predation and 715 selection). This can be conducted e.g. by sensitivity analyses informed by physiological and 716 ecological results, and by including multiple aggregate parameterisations to reflect some 717 level of variation. 
718 Advancements are necessary in the individual-level integration of multiple drivers, which

719 can be informed by results from specifically designed experiments. Models will benefit

720 from the integration of data on energy allocation and well-established physiological

721 performance measures, such as aerobic scope, to define habitat suitability under driver

722 combinations (Teal et al., 2015). These can be used to integrate experimental results

723 directly into hydrodynamic and biogeochemical models (e.g. Cucco et al., 2012). Integrative

724 concepts such as scope for activity (Claireaux and Lefrancois, 2007) and oxygen- and

725 capacity-limited thermal tolerance (OCLTT; Pörtner, 2010) can be used to reduce

726 complexity of representation and serve as a matrix for integration of multiple driver effects

727 in order to generalize organismal performance and stress sensitivity (Pörtner, 2012).

728 Models should also increasingly incorporate dynamic responses, to account for acclimation

729 and evolution. Laboratory measurements of organismal acclimation and phenotypic

730 response variation within populations, as well as knowledge of the functional mechanisms

731 underlying organismal responses, can help to estimate organismal adaptive capacity (see

732 also question 2).

Question 2: How will climate change affect the population dynamics of fish stocks

734 and what is their capacity for adaptation?

735 To assess fish stock responses to climate change, integration of the population level

736 processes recruitment and reproduction, and of the adaptation capacity of populations is

737 needed. Recent meta-analyses and statistical models show that for many stocks,

738 recruitment may be strongly dependent on the environment (Ottersen et al., 2013,

739 Szuwalski et al., 2014, Pecuchet et al., 2015). Data from different early life stages, the 
740 reproduction process and from trans-generational experiments can contribute to create a

741 more mechanistic description of the environmental dependence of population dynamics

742 and to determine the capacity of stocks to undergo adaptation.

743 Stage-structured single or multi-species population dynamic models can be used to

744 investigate the impacts of environmental change on population size and age structure. The

745 use of generalized stock-recruitment relationships or environmental carrying capacities

746 entails strong assumptions, such as homogeneity of a cohort and of environmental

747 conditions (Metcalfe et al., 2012), and the recruitment function can put considerable

748 uncertainty on projections from these models (e.g. Cabral et al., 2013, Howell et al., 2013).

749 An improved integration of environmental effects could be based on the explicit

750 representation of different early life stages (e.g. eggs, non-feeding and feeding larval

751 stages), as realized in some matrix projection models. To incorporate spatially resolved

752 habitat drivers of population processes, increasing focus should also be put on the

753 development of mechanistic SDMs that incorporate stage-structured population dynamic

754 models, as they have been realized for terrestrial systems (e.g. Keith et al., 2008, Fordham

755 et al., 2013, Lurgi et al., 2014).

756 For a more detailed investigation of population structure across life stages and to

757 investigate population adaptation based on acclimation and evolution, trait-based models

758 and IBMs making use of heritable, physiology-based traits will play an important role.

759 While next-generation population genomic methods will help to link genotype and

760 phenotype (Hemmer-Hansen et al., 2014), laboratory studies on organismal tolerance

761 ranges and individual adaptation can help to identify plasticity and within-population 
762 variation in phenotypic traits. Investigation of adaption will advance further once gene

763 expression can be more precisely linked to physiological functions and environmental

764 performance, making use of transcriptomic data and transgenerational experiments

765 (Munday, 2014, Logan and Buckley, 2015). This approach would improve mechanistic

766 understanding of acclimation and evolution (Whitehead, 2012, Alvarez et al., 2015) and

767 could be informed by data gained from 'common garden' experiments with fish from

768 different environmental conditions (e.g. Oomen and Hutchings, 2015) and from laboratory

769 experiments (Munday et al., 2013b). Investigations for early life stages can be

770 complemented by large-scale manipulations conducted e.g. in mesocosms (cf. Munday et

771 al., 2013b, Stewart et al., 2013).

772 Thus, using genetic data and physiological knowledge, exploratory studies about detailed

773 scaling of key processes from organism to population level may succeed when using trait-

774 based models or IBMs that integrate key traits for physiological mechanisms (cf. Reuter et

775 al., 2008). Behavioural traits mediate a wide range of organism-organism and organism-

776 habitat interactions in fish (Munday et al., 2013b, Nagelkerken and Munday, 2015), and

777 thus may become valuable in modelling phenotypic variation and adaptive potential in the

778 context of communities and ecosystems (e.g. Giske et al., 2014). Most trait-based models,

779 however, currently include only a low number of different traits. In IBMs, 'super-

780 individuals' can represent a variable number of real individuals (Scheffer et al., 1995). This

781 concept can be used to scale up organismal properties to higher-level dynamics,

782 maintaining self-organised population properties (Reuter et al., 2005) while limiting

783 computational demands. It has been extended into grid-based approaches, for community 
784 size-spectra in OSMOSE (Shin and Cury 2004) and for sardine and anchovy in the

785 Californian Current in NEMURO.FISH (Fiechter et al., 2015, Rose et al., 2015).

\section{Question 3: Will marine food webs be resilient to climate change, or can regime} shifts occur?

788

789

790

791

792

793

794

795

796

797

798

799

800

801

802

803

804

Regime shifts in marine ecosystems can have strong impacts on fish stocks and are difficult to predict (Frank et al., 2005, deYoung et al., 2008), but community responses to environmental drivers may be crucially determined by characteristics of food web interactions (Mangel and Levin, 2005, Hunsicker et al., 2011, Plaganyi et al., 2014a). Food web topology can be elucidated by analysing biochemical tracers such as stable isotopes and fatty acids (Young et al., 2015). Experimental results on feeding parameters, predation behaviour (e.g. prey switching) and size-dependence can help to detail the interactions and mechanistically describe changes in community-level processes under multiple climate change drivers (Stefansson, 2003, Persson et al., 2014, Nagelkerken and Munday, 2015).

In trophic mass-balance models such as EwE and in end-to-end models, different types of trophic control (bottom-up, top-down, or a mixture) can be integrated through vulnerability parameters (e.g. Ahrens et al., 2012), and network analysis indicators can be used to characterize the resulting food web dynamics and identify key functional groups (Heymans et al., 2014). Yet, aiming for a complete representation of food webs causes a comparatively high need for field data, especially when analysing dynamics over time.

Multi-species stock models are less data demanding and have been used to compare conditions for regime shifts and thresholds among different systems (e.g. Petrie et al., 2009, 
805 Plaganyi et al., 2014a). Their simplified structure should be informed by ecological 806 knowledge, such as identification of major trophic pathways and selection of key 807 components (Gilman et al., 2010, Shin et al., 2010), network analysis of more complex 808 models (e.g. Metcalf et al., 2008, Livi et al., 2011), or 'ecotypes' that represent mixed 809 ecological characteristics (Engelhard et al., 2010).

810 Size spectrum models can investigate food web dynamics based on size structure (e.g. 811 Blanchard et al., 2010), but representation of other properties that affect interactions is 812 currently limited. To quantitatively characterize the vulnerability of interaction processes 813 to predator/prey or environmental changes, IBMs and trait-based models can use 814 behavioural rules and inter-individual variability to produce emergent feeding interactions, 815 instead of relying on a statistical functional response (Fiksen et al., 2007, Mariani and 816 Visser, 2010). Understanding of marine ecosystem resilience under climate change could 817 be advanced by trait-based models with a focus on ecologically functional traits (Bremner, 818 2008, Mouillot et al., 2013) and by multi-species IBMs that use empirical results on food 819 uptake, energy allocation and predation behaviour to set parameter values (see 'Coupled 820 and end-to-end models'). Predation and energy allocation are key processes to link fish 821 models to lower trophic level changes (Cury et al., 2008), and a realistic two-way coupling 822 is necessary to describe ecosystem dynamics, especially in top-down controlled systems 823 (Travers et al., 2009, Daewel et al., 2014).

824 To provide data for parameterization of these models, more systematic experimental 825 investigation of environmental influences on foraging and assimilation processes is 826 necessary. The effects of different functional response formulations on model behaviour 
827 should be tested more routinely, and whenever feasible, relevant behavioural and habitat 828 aspects be represented dynamically. Options include using integrative suitability or 829 vulnerability settings (e.g. Kempf et al., 2010, Ahrens et al., 2012) and multi-dimensional 830 functional responses (e.g. Büssenschütt and Pahl-Wostl, 2000, Dawes and Souza, 2013).

831 These community models can then inform spatially resolved models to explore how local 832 food web dynamics respond to changes in spatial distribution of species abundance.

\section{Question 4: How will the spatial distribution and range of stocks change?}

834 This research question combines data on different levels of biological organization (cf. Fig.

835 1), as individual responses to local environmental factors (e.g. temperatures, oxygen

836 levels), adaptation and changes in recruitment, food web interactions, and dispersal and

837 habitat availability all influence the distribution of fish stocks (Roessig et al., 2005, Rose, 838 2005, Hollowed et al., 2013).

839 Spatial variability is well represented in Species Distribution Models. SDMs have advanced 840 considerably in incorporating details on organism-level processes, population dynamics, 841 competition and spatial-temporal processes, and can be based upon experimental results 842 on different levels, as exemplified for acidification and warming effects on a marine 843 invertebrate species (Queirós et al., 2015). Underlying assumptions of steady-state 844 relations in SDMs should always be critically examined (e.g. Guisan and Thuiller, 2005, 845 Knudby et al., 2010). Additional empirical results should be used to consider potentially 846 critical effects in processes not explicitly represented, e.g. recruitment, population 847 adaptation, migration and dispersal, and changes in species interactions (cf. Brander et al., 848 2013). 
849 Further development of SDMs in the marine realm should also be inspired from extensive 850 experience with related models in terrestrial applications, especially with respect to 851 dynamic (state-dependent) integration of population and community level processes 852 (Robinson et al., 2011, Fordham et al., 2013) and to physiological limits and adaptive 853 evolution (Catullo et al., 2015), although not all concepts may be transferable to marine 854 systems. The trophodynamic model Ecospace offers functionality similar to SDMs in its 855 'habitat capacity' response functions, with dynamic integration of spatial processes into the 856 food web context and the option to link to spatial-temporal input (Steenbeek et al., 2013, 857 Christensen et al., 2014a). As end-to-end models usually resolve spatial and community 858 processes, they possess high capacity for more integrative projections of distribution 859 changes (e.g. Rose et al., 2015).

860 IBMs have been used to describe larval growth and dispersal in high spatial resolution and 861 integrate sampling data (Lett et al., 2010, Hidalgo et al., 2012). Energy allocation principles 862 may be able to trace recruitment success and the evolution of spawning migrations, but 863 need to be informed by more experimental research and coupled between all life stages (cf. 864 Fiksen et al., 2007, Peck and Hufnagl, 2012). Integrative physiological concepts may be 865 used to generalize changes in relative performance of interacting or competing species 866 (Pörtner and Farrell, 2008, Pörtner, 2012). Additionally, more observational, telemetric 867 and demographic data will be needed to improve incorporation of spatial structure and 868 processes (Runge et al., 2010, Metcalfe et al., 2012).

869 The incorporation of active migration of later life stages and of spatially resolved and 870 potentially patchy distribution of spawning habitat, and in general the integration of lower 
871 and higher level processes represent significant challenges in achieving reliable projections

872 about spatial shifts of fish stocks under climate change. In the near future, these challenges

873 will probably be handled using coupling of different modelling approaches and end-to-end

874 models along with case-dependent strategies for reduction of complexity. In the meantime,

875 adequate use of simpler representations will remain valuable for management and policy

876 advice.

877 Question 5: What will be the socio-economic impacts and the implications for 878 management of changing marine ecosystems?

879 Climate-mediated changes in marine ecosystems and fish stocks can have different socio-

880 economic effects in different regions and affect a range of ecosystem services used by

881 human societies (Cooley et al., 2009, Sumaila et al., 2011, Pörtner et al., 2014). Climate

882 change effects can interact with human uses, e.g. by fishing, and can be modified by other

883 short-term anthropogenic drivers such as eutrophication or pollution and amplified or

884 even overridden by general socio-economic developments (Perry et al., 2010). Therefore,

885 an analysis of ecosystem impacts of climate change in exploited marine systems, and

886 especially the assessment of their socio-economic consequences, need to link biological and

887 socio-economic research approaches, building on an identification of involved ecological

888 processes and incorporating interactions with human societies (Le Quesne and Pinnegar,

889 2012, Hilmi et al., 2013).

890 Different model classes have been used to assess management or adaptation strategies to

891 climate change effects for fish stocks and marine ecosystems, but societal dynamics have

892 until recently received little attention (Barange et al., 2010). Socio-economic dynamics and 
893 background scenarios related to fish markets have been integrated into extended

894 population dynamic or 'bioeconomic' models (e.g. Merino et al., 2010, Norman-Lopez et al., 895 2013), species distribution models (Cheung et al., 2010, Jones et al., 2014), mass-balance 896 models (Christensen et al., 2015), size spectrum and trait-based models (Woodworth897 Jefcoats et al., 2013, Barange et al., 2014, Zimmermann and Jorgensen, 2015) and the end898 to-end model Atlantis (Fulton et al., 2011, Griffith et al., 2012).

899 Societies have a range of adaptation options to climate change-induced changes, e.g. 900 increase of fishing effort, economic diversification, or change of fishing grounds (Perry et 901 al., 2011). Incorporating adaptive societal responses and their social and cultural 902 conditions, based on observations and models, can enable improved governance and 903 increase resilience of marine social-ecological systems (Folke, 2006, Miller et al., 2010, 904 Schlüter et al., 2012). Societal dynamics can be implemented e.g. using network models 905 (Janssen et al., 2006) or arising from individual actor behaviour in 'agent-based' models 906 (Gilbert and Terna, 2000).

907 The advancement of integrated models is promising to achieve more accurate projections 908 of the future states of social-ecological systems (Österblom et al., 2013, Griffith and Fulton, 909 2014), and models for informing fisheries management under changing environmental 910 drivers have been developed (e.g. Cooley et al., 2015). Advances are necessary in

911 identifying specific societal adaptive capacities in response to regionally expected impacts 912 of climate change, based on reliable quantitative data. Beyond fisheries, quantification of 913 impacts of other marine industries and on the provision of other marine ecosystem 914 services is needed, such as tourism, carbon sequestration, or coastal protection (cf. 
915 Beaumont et al., 2007, Liquete et al., 2013). Conceptual challenges relate to scale

916 differences and the identification of processes which determine adaptive capacities of

917 natural and social systems (Perry and Ommer, 2003, Griffith and Fulton, 2014).

\section{Conclusions}

919 The integration of physiological and ecological processes has great potential to advance 920 ecological models for fish stocks. Representation of mechanisms mediating climate effects

921 can be increased by 1) identifying key processes for the question of interest across levels of 922 organization, 2) using and coupling models which represent the key processes, and 3)

923 incorporating experimental results from a range of conditions and across life history stages 924 and generations.

925 For investigating the direct effects of multiple environmental drivers on fish, models should 926 be adapted sensibly to integrate experimental data and investigate organism-level trade927 offs and sensitivities, e.g. by making use of energy allocation principles. The investigation of 928 changes in population dynamics can benefit from increased model detail in the 929 representation of effects on early life stages and reproduction. Understanding of 930 acclimation and evolution under climate change can be advanced by assessment of 931 functional traits and specifically designed experiments. Marine community shifts under 932 multiple drivers can be better anticipated by analysis of food web structure and 933 quantification of functional responses. Research on stock distribution shifts and socio934 economic impacts of changes in marine living resources should increasingly incorporate 935 results on the co-determination of spatial movement and dispersal by behavioural fish 936 responses and trade-offs in energy allocation and community interactions, and improve the 
937 integration of societal dynamics. Coupling of models to address these higher-order

938 questions can be informed e.g. by data on food energy content and transfer, and by

939 behavioural observations of fish and people.

940 Improvements in projection capacities by integrating these processes, and potential trade-

941 offs e.g. with regard to parameter uncertainties, will have to be verified on a case-to-case

942 basis. Scaling issues will have to be addressed to reduce the complexity of models while

943 maintaining sensitivities across scales: a focus should be put on the identification of

944 mechanisms and techniques that span levels of description and can couple specialized

945 models without levelling out heterogeneity and variability at lower levels that may be

946 decisive for higher level dynamics. Examples include the super-individual concept in

947 individual-based models and physiological concepts for estimating organism sensitivity

948 towards multiple drivers.

949 To this end, planning of experiments and structuring of models should be coordinated

950 more closely in the research process and based on an improved dialogue between

951 modellers and experimentalists. This will warrant meaningful physiological experiments

952 and an improved integration of both empirical results and mechanistic understanding of

953 effects into existing and future models.

\section{Acknowledgements}

955 SK and FCM are currently funded through the research program BIOACID (Biological

956 Impacts of Ocean Acidification, phase II), by the German Federal Ministry of Education and

957 Research (BMBF, FKZ 03F0655B and 03F0655J). SK gratefully acknowledges additional 
958 support through travel grants to relevant international conferences, from ICES

959 (International Council for the Exploration of the Sea), SCOR (Scientific Committee on Ocean

960 Research), the University of Bremen Central Research Development Fund, the German

961 Academic Exchange Service (DAAD) and LabexMer. HOP acknowledges funding through

962 BIOACID and the PACES program of AWI. The authors would like to thank Marta Coll

963 (IRD/IFREMER/CSIC), Øyvind Fiksen (University of Bergen), Bjarte Bogstad (IMR Bergen)

964 and three anonymous reviewers for valuable comments and suggestions that helped to

965 improve the final manuscript.

\section{References}

967 Ahrens, R.N.M., Walters, C.J., Christensen, V. (2012) Foraging arena theory. Fish and Fisheries 968 13, 41-59.

969 Ainsworth, C.H., Samhouri, J.F., Busch, D.S., Cheung, W.W.L., Dunne, J., Okey, T.A. (2011)

970 Potential impacts of climate change on Northeast Pacific marine foodwebs and fisheries.

971 ICES Journal of Marine Science 68, 1217-1229.

972 Albouy, C., Velez, L., Coll, M., et al. (2014) From projected species distribution to food-web 973 structure under climate change. Global Change Biology 20, 730-741.

974 Alvarez, M., Schrey, A.W., Richards, C.L. (2015) Ten years of transcriptomics in wild 975 populations: what have we learned about their ecology and evolution? Molecular ecology $97624,710-725$.

977 Andersen, K.H., Beyer, J.E. (2006) Asymptotic size determines species abundance in the marine 978 size spectrum. American Naturalist 168, 54-61. 
979 Andersen, K.H., Beyer, J.E. (2013) Size structure, not metabolic scaling rules, determines 980 fisheries reference points. Fish and Fisheries 16, 1-22.

981 Andersen, K.H., Brander, K. (2009) Expected rate of fisheries-induced evolution is slow. 982

983 Proceedings of the National Academy of Sciences of the United States of America 106, 11657 11660.

984

Anderson, J.J., Gurarie, E., Bracis, C., Burke, B.J., Laidre, K.L. (2013) Modeling climate change 985

986 impacts on phenology and population dynamics of migratory marine species. Ecological

987 Modelling 264, 83-97.

Andrews, J.M., Gurney, W.S.C., Heath, M.R., et al. (2006) Modelling the spatial demography of 988 Atlantic cod (Gadus morhua) on the European continental shelf. Canadian Journal of 989 Fisheries and Aquatic Sciences 63, 1027-1048.

990

Araújo, J.N., Bundy, A. (2012) Effects of environmental change, fisheries and trophodynamics 991

992 on the ecosystem of the western Scotian Shelf, Canada. Marine Ecology Progress Series 464, 51-67.

993

Araújo, M.B., Guisan, A. (2006) Five (or so) challenges for species distribution modelling. 994 Journal of Biogeography 33, 1677-1688.

995 Araújo, M.B., Rozenfeld, A. (2014) The geographic scaling of biotic interactions. Ecography 37, 996 $406-415$.

997

Arunachalam, S., Zalila-Wenkstern, R., Steiner, R. (2008) Environment mediated Multi Agent 998

999 Simulation Tools-A Comparison. Sasow 2008: Second Ieee International Conference on SelfAdaptive and Self-Organizing Systems Workshops, Proceedings, 43-48.

Asch, R.G. (2015) Climate change and decadal shifts in the phenology of larval fishes in the 1001 California Current ecosystem. Proceedings of the National Academy of Sciences 112, E40651002 E4074. 
1003 Austin, M. (2007) Species distribution models and ecological theory: A critical assessment and 1004 some possible new approaches. Ecological Modelling 200, 1-19.

1005

Barange, M., Cheung, W.W.L., Merino, G., Perry, R.I. (2010) Modelling the potential impacts 1006

1007 of climate change and human activities on the sustainability of marine resources. Current Opinion in Environmental Sustainability 2, 326-333.

1008

Barange, M., Merino, G., Blanchard, J.L., et al. (2014) Impacts of climate change on marine 1009

1010 ecosystem production in societies dependent on fisheries. Nature Clim. Change 4, 211216.

1011

1012

1013

Baskett, M.L. (2012) Integrating mechanistic organism-environment interactions into the basic

1014

Baudron, A.R., Needle, C.L., Rijnsdorp, A.D., Marshall, C.T. (2014) Warming temperatures and 1015 smaller body sizes: synchronous changes in growth of North Sea fishes. Global Change

1016 Biology 20, 1023-1031.

1017

Baumann, H., Talmage, S.C., Gobler, C.J. (2012) Reduced early life growth and survival in a 1018 fish in direct response to increased carbon dioxide. Nature Climate Change $\mathbf{2}, 38-41$.

1019 Beauchamp, D.A., Cross, A.D., Armstrong, J.L., et al. (2007) Bioenergetic Responses by Pacific 1020 Salmon to Climate and Ecosystem Variation. North Pacific Anadromous Fish Commission 1021 Bulletin 4, 257-269.

1022 Beaugrand, G., Brander, K.M., Alistair Lindley, J., Souissi, S., Reid, P.C. (2003) Plankton effect 1023 on cod recruitment in the North Sea. Nature 426, 661-664.

1024 Beaugrand, G., Kirby, R.R. (2010) Climate, plankton and cod. Global Change Biology 16, 12681025 1280. 
1026 Beaumont, N.J., Austen, M.C., Atkins, J.P., et al. (2007) Identification, definition and

1027

1028

1029

1030

1031

1032

1033

1034

1035

1036

1037

1038

1039

1040

1041

1042

1043

1044

1045

1046

1047

1048 quantification of goods and services provided by marine biodiversity: implications for the ecosystem approach. Marine pollution bulletin 54, 253-265.

Benoit, E., Rochet, M.J. (2004) A continuous model of biomass size spectra governed by predation and the effects of fishing on them. Journal of Theoretical Biology 226, 9-21.

Beverton, R., Holt, S.J. (1957) On the Dynamics of Exploited Fish Populations. Fisheries Investigation Series 2.

Blanchard, J.L., Jennings, S., Holmes, R., et al. (2012) Potential consequences of climate change for primary production and fish production in large marine ecosystems. Philosophical transactions of the Royal Society of London. Series B, Biological sciences 367, 2979-2989.

Blanchard, J.L., Jennings, S., Law, R., et al. (2009) How does abundance scale with body size in coupled size-structured food webs? Journal of Animal Ecology 78, 270-280.

Blanchard, J.L., Law, R., Castle, M.D., Jennings, S. (2010) Coupled energy pathways and the resilience of size-structured food webs. Theoretical Ecology 4, 289-300.

Bogstad, B., Gjøsæter, H., Haug, T., Lindstrøm, U. (2015) A review of the battle for food in the Barents Sea: cod vs. marine mammals. Frontiers in Ecology and Evolution 3, 29.

Bogstad, B., Hauge, K.H., Ulltang, Ø. (1997) MULTSPEC-a multi-species model for fish and marine mammals in the Barents Sea. Journal of Northwest Atlantic Fishery Science 22, 317341.

Brander, K. (2010) Impacts of climate change on fisheries. Journal of Marine Systems 79, 389402.

Brander, K., Mohn, R. (2004) Effect of the North Atlantic Oscillation on recruitment of Atlantic cod (Gadus morhua). Canadian Journal of Fisheries and Aquatic Sciences 61, 1558-1564. 
1049 Brander, K., Neuheimer, A., Andersen, K.H., Hartvig, M. (2013) Overconfidence in model 1050 projections. ICES Journal of Marine Science 70, 1069-1074.

1051 Brander, K.M. (1995) The Effect of Temperature on Growth of Atlantic Cod (Gadus-Morhua 1052 L). ICES Journal of Marine Science 52, 1-10.

1053 Brauner, C.J., Baker, D.W. (2009) Patterns of acid-base regulation during exposure to 1054 hypercarbia in fishes. In: Cardio-Respiratory Control in Vertebrates. (Eds. M.L. Glass, S.C. 1055 Wood), Berlin, pp. 43-63.

1056 Bremner, J. (2008) Species' traits and ecological functioning in marine conservation and 1057 management. Journal of Experimental Marine Biology and Ecology 366, 37-47.

1058 Briffa, M., de la Haye, K., Munday, P.L. (2012) High CO and marine animal behaviour: 1059 potential mechanisms and ecological consequences. Marine pollution bulletin 64, 15191060 1528.

1061 Brown, J.H., Gillooly, J.F., Allen, A.P., Savage, V.M., West, G.B. (2004) Toward a Metabolic 1062 Theory of Ecology. Ecology 85, 1771-1789.

1063 Büssenschütt, M., Pahl-Wostl, C. (2000) A discrete, allometric approach to the modeling of 1064 ecosystem dynamics. Ecological Modelling 126, 33-48.

1065 Cabral, R.B., Aliño, P.M., Lim, M.T. (2013) A coupled stock-recruitment-age-structured model 1066 of the North Sea cod under the influence of depensation. Ecological Modelling 253, 1-8.

1067 Caswell, H. (2001) Matrix population models: construction, analysis, and interpretation, 2nd ed., 1068 Sinauer Associates, Sunderland, MA.

1069 Catullo, R.A., Ferrier, S., Hoffmann, A.A. (2015) Extending spatial modelling of climate change 1070 responses beyond the realized niche: estimating, and accommodating, physiological 1071 limits and adaptive evolution. Global Ecology and Biogeography 24, 1192-1202. 
1072 Chapman, E.W., Jorgensen, C., Lutcavage, M.E. (2011) Atlantic bluefin tuna (Thunnus

1073

1074

1075

1076

1077

1078

1079

1080

1081

1082

1083

1084

1085

1086

1087

1088

1089

1090

1091

1092

1093

1094 thynnus): a state-dependent energy allocation model for growth, maturation, and reproductive investment. Canadian Journal of Fisheries and Aquatic Sciences 68, 19341951.

Cheung, W., Lam, V., Sarmiento, J.L. (2009) Projecting global marine biodiversity impacts under climate change scenarios - Cheung. Fish and Fisheries 10.

Cheung, W.W.L., Dunne, J., Sarmiento, J.L., Pauly, D. (2011) Integrating ecophysiology and plankton dynamics into projected maximum fisheries catch potential under climate change in the Northeast Atlantic. ICES Journal of Marine Science 68, 1008-1018.

Cheung, W.W.L., Lam, V.W.Y., Pauly, D. (2008) Dynamic Bioclimate Envelope Model to Predict Climate-Induced Changes in Distribution of Marine Fishes and Invertebrates. Fisheries Centre Research Reports, 5-50.

Cheung, W.W.L., Lam, V.W.Y., Sarmiento, J.L., et al. (2010) Large-scale redistribution of maximum fisheries catch potential in the global ocean under climate change. Global Change Biology 16, 24-35.

Chown, S.L. (2012) Trait-based approaches to conservation physiology: forecasting environmental change risks from the bottom up. Philosophical transactions of the Royal Society of London. Series B, Biological sciences 367, 1615-1627.

Chown, S.L., Hoffmann, A.A., Kristensen, T.N., Angilletta, M.J., Stenseth, N.C., Pertoldi, C. (2010) Adapting to climate change: a perspective from evolutionary physiology. Climate Research 43, 3-15.

Christensen, V., Coll, M., Buszowski, J., et al. (2015) The global ocean is an ecosystem: simulating marine life and fisheries. Global Ecology and Biogeography 24, 507-517. 
1095 Christensen, V., Coll, M., Steenbeek, J., Buszowski, J., Chagaris, D., Walters, C.J. (2014a) 1096 Representing Variable Habitat Quality in a Spatial Food Web Model. Ecosystems.

1097 Christensen, V., de la Puente, S., Sueiro, J.C., Steenbeek, J., Majluf, P. (2014b) Valuing seafood: 1098 The Peruvian fisheries sector. Marine Policy 44, 302-311.

1099 Christensen, V., Walters, C.J. (2004) Ecopath with Ecosim: methods, capabilities and $1100 \quad$ limitations. Ecological Modelling 172, 109-139.

1101 Chung, W.S., Marshall, N.J., Watson, S.A., Munday, P.L., Nilsson, G.E. (2014) Ocean 1102

1103 acidification slows retinal function in a damselfish through interference with GABA(A) receptors. Journal of Experimental Biology 21 7, 323-326.

1104 Ciannelli, L., Fauchald, P., Chan, K.S., Agostini, V.N., Dingsor, G.E. (2008) Spatial fisheries 1105 ecology: Recent progress and future prospects. Journal of Marine Systems 7 1, 223-236.

Ciannelli, L., Fisher, J.A.D., Skern-Mauritzen, M., et al. (2013) Theory, consequences and evidence of eroding population spatial structure in harvested marine fishes: a review. Marine Ecology Progress Series 480, $227-243$.

1109

1110

1111

1112

1114

1115 1116

1117 1118

Claireaux, G., Lefrancois, C. (2007) Linking environmental variability and fish performance: integration through the concept of scope for activity. Philosophical Transactions of the Royal Society B-Biological Sciences 362, $2031-2041$.

Clark, R.A., Fox, C.J., Viner, D., Livermore, M. (2003) North Sea cod and climate change modelling the effects of temperature on population dynamics. Global Change Biology $\mathbf{9}$, 1669-1680.

Clarke, A., Johnston, N.M. (1999) Scaling of metabolic rate with body mass and temperature in teleost fish. Journal of Animal Ecology 68, 893-905.

Cochrane, K.L., Perry, R.I., Daw, T.M., Soto, D., Barange, M., De Silva, S.S. (2009) Climate change implications for fisheries and aquaculture: overview of current scientific knowledge. FAO 

fisheries and aquaculture technical paper Vol. 530, Food and Agriculture Organization of the United Nations, Rome.

1121 Cooley, S.R., Kite-Powell, H.L., Doney, S.C., Act, A. (2009) Ocean acidification’s potential to alter global marine ecosystem services. 22, 172-181.

1123 Cooley, S.R., Rheuban, J.E., Hart, D.R., et al. (2015) An Integrated Assessment Model for $1124 \quad$ Helping the United States Sea Scallop (Placopecten magellanicus) Fishery Plan Ahead for Ocean Acidification and Warming. PloS one 10.

1126

1127

1128

1129

1130

1132

1133

1134

1135

1136

1138

1139

1140

1141

Cornwall, C.E., Eddy, T.D. (2015) Effects of near-future ocean acidification, fishing, and marine protection on a temperate coastal ecosystem. Conservation Biology 29, 207-215.

Costanza, R., Ruth, M. (1998) Using dynamic modeling to scope environmental problems and build consensus. Environmental Management 22, 183-195.

Couturier, C.S., Stecyk, J.A.W., Rummer, J.L., Munday, P.L., Nilsson, G.E. (2013) Speciesspecific effects of near-future $\mathrm{CO} 2$ on the respiratory performance of two tropical prey fish and their predator. Comparative Biochemistry and Physiology Part A: Molecular Eamp; Integrative Physiology 166, 482-489.

Crozier, L.G., Hutchings, J.A. (2014) Plastic and evolutionary responses to climate change in fish. Evolutionary Applications 7, 68-87.

Cucco, A., Sinerchia, M., Lefrançois, C., et al. (2012) A metabolic scope based model of fish response to environmental changes. Ecological Modelling 237, 132-141.

Cury, P.M., Shin, Y.J., Planque, B., et al. (2008) Ecosystem oceanography for global change in fisheries. Trends in Ecology Eீ Evolution 23, 338-346.

Daewel, U., Hjollo, S.S., Huret, M., et al. (2014) Predation control of zooplankton dynamics: a review of observations and models. ICES Journal of Marine Science 7 1, 254-271. 
1142 Daewel, U., Peck, M.A., Schrum, C., St John, M.A. (2008) How best to include the effects of

1143

1144

1145

1146

1148

1149

1150

1151

1152

1153

1154

1155

1156

1157

1158

1159

1160

1161

1162

1163

1164

climate-driven forcing on prey fields in larval fish individual-based models. Journal of Plankton Research 30, 1-5.

Dalpadado, P., Ingvaldsen, R.B., Stige, L.C., et al. (2012) Climate effects on Barents Sea ecosystem dynamics. ICES Journal of Marine Science 69, 1303-1316.

Dawes, J.H.P., Souza, M.O. (2013) A derivation of Holling's type I, II and III functional responses in predator-prey systems. Journal of Theoretical Biology 327, 11-22.

de Mutsert, K., Steenbeek, J., Lewis, K., Buszowski, J. (2015) Exploring effects of hypoxia on fish and fisheries in the northern Gulf of Mexico using a dynamic spatially explicit ecosystem model. Ecological Modelling (2015).

Deigweiher, K., Koschnick, N., Portner, H.O., Lucassen, M. (2008) Acclimation of ion regulatory capacities in gills of marine fish under environmental hypercapnia. American Journal of Physiology- Regulatory, Integrative and Comparative Physiology 295, R1660R1670.

Denman, K., Christian, J.R., Steiner, N., Portner, H.O., Nojiri, Y. (2011) Potential impacts of future ocean acidification on marine ecosystems and fisheries: current knowledge and recommendations for future research. ICES Journal of Marine Science 68, 1019-1029.

Denny, M., Helmuth, B. (2009) Confronting the physiological bottleneck: A challenge from ecomechanics. Integrative and comparative biology 49, 197-201.

Deriso, R.B., Quinn, I., T J, Neal, P.R. (1985) Catch-Age Analysis with Auxiliary Information. Canadian Journal of Fisheries and Aquatic Sciences 42, 815-824.

Devine, B.M., Munday, P.L., Jones, G.P. (2012) Homing ability of adult cardinalfish is affected by elevated carbon dioxide. Oecologia 168, 269-276. 
1165 deYoung, B., Barange, M., Beaugrand, G., et al. (2008) Regime shifts in marine ecosystems: detection, prediction and management. Trends in Ecology Eீ Evolution 23, 402-409.

Diamond, S.L., Murphy, C.A., Rose, K.A. (2013) Simulating the effects of global climate change on Atlantic croaker population dynamics in the mid-Atlantic Region. Ecological Modelling 264, 98-1 14 .

Donelson, J.M., Munday, P.L. (2012) Thermal sensitivity does not determine acclimation capacity for a tropical reef fish. Journal of Animal Ecology 81, 1126-1131.

Doney, S.C., Ruckelshaus, M., Emmett Duffy, J., et al. (2012) Climate Change Impacts on Marine Ecosystems. Annual Review of Marine Science 4, 11-37.

Dormann, C.F. (2007) Promising the future? Global change projections of species distributions. Basic and Applied Ecology 8, 387-397.

Dunlop, E.S., Heino, M., Dieckmann, U. (2009) Eco-genetic modeling of contemporary lifehistory evolution. Ecological Applications 19, 1815-1834.

Dupont, S., Pörtner, H.O. (2013) A snapshot of ocean acidification research. Marine Biology 160, $1765-1771$.

Ekau, W., Auel, H., Pörtner, H.O., Gilbert, D. (2010) Impacts of hypoxia on the structure and processes in pelagic communities (zooplankton, macro-invertebrates and fish). Biogeosciences 7, 1669-1699.

Elith, J., Leathwick, J.R. (2009) Species Distribution Models: Ecological Explanation and Prediction Across Space and Time. Annual Review of Ecology, Evolution, and Systematics 40, 677-697.

Engelhard, G.H., Ellis, J.R., Payne, M.R., ter Hofstede, R., Pinnegar, J.K. (2010) Ecotypes as a concept for exploring responses to climate change in fish assemblages. ICES Journal of Marine Science, 1-12. 
1189 Engelhard, G.H., Peck, M.A., Rindorf, A., et al. (2014) Forage fish, their fisheries, and their predators: who drives whom? ICES Journal of Marine Science 7 1, 90-104.

1191 Enzor, L.A., Zippay, M.L., Place, S.P. (2013) High latitude fish in a high CO2 world: Synergistic effects of elevated temperature and carbon dioxide on the metabolic rates of Antarctic notothenioids. Comparative Biochemistry and Physiology a-Molecular $\Xi^{\circ}$ Integrative Physiology 164, 154-161.

Evans, K., Brown, J.N., Sen Gupta, A., et al. (2015) When 1+1 can be > 2: Uncertainties compound when simulating climate, fisheries and marine ecosystems. Deep-Sea Research Part II-Topical Studies in Oceanography 113, 312-322.

Fabry, V.J., Seibel, B.A., Feely, R.A., Orr, J.C. (2008) Impacts of ocean acidification on marine 1200 fauna and ecosystem processes. ICES Journal of Marine Science 65, 414-432.

Fernandes, J.A., Cheung, W.W.L., Jennings, S., et al. (2013) Modelling the effects of climate 1201

1202

1203 change on the distribution and production of marine fishes: accounting for trophic interactions in a dynamic bioclimate envelope model. Global Change Biology 19, 25962607.

1204 Ferrari, M.C., Manassa, R.P., Dixson, D.L., et al. (2012) Effects of ocean acidification on $1205 \quad$ learning in coral reef fishes. PloS one 7.

1206 Ferrari, M.C.O., McCormick, M.I., Munday, P.L., et al. (2011) Putting prey and predator into 1207 1208 the $\mathrm{CO} 2$ equation - qualitative and quantitative effects of ocean acidification on predator-prey interactions. Ecology letters 14, 1143-1148.

1209 Fiechter, J., Rose, K.A., Curchitser, E.N., Hedstrom, K.S. (2015) The role of environmental 1210 1211 Current: Analysis of an end-to-end model. Progress in Oceanography 138, 381-398. 
1212 Field, J.C., Francis, R.C., Aydin, K. (2006) Top-down modeling and bottom-up dynamics:

1213

1214

1215

1216

1217

1218

1219

1220

1221

1222

1223

1224

1225

1226

1227

1228

1229

1230

1231

1232

1233 Linking a fisheries-based ecosystem model with climate hypotheses in the Northern California Current. Progress in Oceanography 68, 238-270.

Fiksen, O., Jørgensen, C. (2011) Model of optimal behaviour in fish larvae predicts that food availability determines survival, but not growth. Marine Ecology Progress Series 432, 207-219.

Fiksen, Ø., Jørgensen, C., Kristiansen, T., Vikebø, F., Huse, G. (2007) Linking behavioural ecology and oceanography: larval behaviour determines growth, mortality and dispersal. Marine Ecology Progress Series 347, 195-205.

Folke, C. (2006) Resilience: The emergence of a perspective for social-ecological systems analyses. Global Environmental Change 16, 253-267.

Fordham, D.A., Akcakaya, H.R., Araujo, M.B., Keith, D.A., Brook, B.W. (2013) Tools for integrating range change, extinction risk and climate change information into conservation management. Ecography 36, 956-964.

Fournier, D.A., Hampton, J., Sibert, J.R. (1998) MULTIFAN-CL: a length-based, agestructured model for fisheries stock assessment, with application to South Pacific albacore, Thunnus alalunga. Canadian Journal of Fisheries and Aquatic Sciences 55, 21052116.

Fournier, D.A., Sibert, J.R., Majkowski, J., Hampton, J. (1990) Multifan a Likelihood-Based Method for Estimating Growth-Parameters and Age Composition from Multiple Length Frequency Data Sets Illustrated Using Data for Southern Bluefin Tuna (Thunnus-Maccoyii). Canadian Journal of Fisheries and Aquatic Sciences 47, 301-317. 
1234 Fouzai, N., Coll, M., Palomera, I., Santojanni, A., Arneri, E., Christensen, V. (2012) Fishing

1235

1236

1237

1238

1239

1240

1241

1242

1243

1244

1245

1246

1247

1248

1249

1250

1251

1253

1254

1255

1256 management scenarios to rebuild exploited resources and ecosystems of the NorthernCentral Adriatic (Mediterranean Sea). Journal of Marine Systems 102, 39-51.

Frank, K.T., Petrie, B., Choi, J.S., Leggett, W.C. (2005) Trophic cascades in a formerly coddominated ecosystem. Science 308, $1621-1623$.

Frank, K.T., Petrie, B., Shackell, N.L., Choi, J.S. (2006) Reconciling differences in trophic control in mid-latitude marine ecosystems. Ecology letters $\mathbf{9 ,}$ 1096-1 105.

Franke, A., Clemmesen, C. (2011) Effect of ocean acidification on early life stages of Atlantic herring (Clupea harengus L.). Biogeosciences Discussions 8, 7097-7126.

Freitas, V., Cardoso, J.F.M.F., Lika, K., et al. (2010) Temperature tolerance and energetics: a dynamic energy budget-based comparison of North Atlantic marine species. Philosophical transactions of the Royal Society of London. Series B, Biological sciences 365, $3553-3565$.

Frommel, A., Maneja, R., Lowe, D., et al. (2012) Severe tissue damage in Atlantic cod larvae under increasing ocean acidification. Nature Climate Change 2, 42-46.

Frommel, A., Stiebens, V., Clemmesen, C., Havenhand, J. (2010) Effect of ocean acidification on marine fish sperm (Baltic cod: Gadus morhua). Biogeosciences Discussions 7, 5859-5872.

Frøysa, K.G., Bogstad, B., Skagen, D.W. (2002) Fleksibest - an age-length structured fish stock assessment model. Fisheries Research 55, 87-101.

Fulton, E.A. (2010) Approaches to end-to-end ecosystem models. Journal of Marine Systems 81, 171-183.

Fulton, E.A., Gorton, R. (2014) Adaptive futures for SE Australian Fisheries \& Aquaculture: Climate Adaptation Simulations. CSIRO, Australia. 
1257 Fulton, E.A., Link, J.S., Kaplan, I.C., et al. (2011) Lessons in modelling and management of marine ecosystems: the Atlantis experience. Fish and Fisheries 12, 171-188.

1259 Fulton, E.A., Parslow, J.S., Smith, A.D.M., Johnson, C.R. (2004) Biogeochemical marine

1260

1261

1262

1263

1264

1265

1266

1267

1268

1269

1270

1271

1272

1273

1274

1275

1276

1277

1278 ecosystem models II: the effect of physiological detail on model performance. Ecological Modelling 173, 371-406.

Fulton, E.A., Smith, A.D.M., Johnson, C.R. (2003) Effect of complexity on marine ecosystem models. Marine Ecology Progress Series 253, 1-16.

Gallego, A., North, E.W., Petitgas, P. (2007) Introduction: status and future of modelling physical-biological interactions during the early life of fishes. Marine Ecology Progress Series 347, 12 1-126.

Garrison, L.P., Link, J.S., Kilduff, D.P., et al. (2010) An expansion of the MSVPA approach for quantifying predator-prey interactions in exploited fish communities. ICES Journal of Marine Science 67, 856-870.

Gascuel, D., Guenette, S., Pauly, D. (2011) The trophic-level-based ecosystem modelling approach: theoretical overview and practical uses. ICES Journal of Marine Science 68, 1403-1416.

Gascuel, D., Pauly, D. (2009) EcoTroph: Modelling marine ecosystem functioning and impact of fishing. Ecological Modelling 220, 2885-2898.

Gaylord, B., Kroeker, K.J., Sunday, J.M., et al. (2015) Ocean acidification through the lens of ecological theory. Ecology 96, 3-15.

Gilbert, N., Terna, P. (2000) How to build and use agent-based models in social science. Mind E Society 1, 57-72. 
1279 Gilman, S.E., Urban, M.C., Tewksbury, J., Gilchrist, G.W., Holt, R.D. (2010) A framework for 1280

1281 community interactions under climate change. Trends in Ecology \&o Evolution 25, 325-

1282

Giske, J., Eliassen, S., Fiksen, Ø., et al. (2014) The emotion system promotes diversity and 1283 evolvability. Proceedings of the Royal Society B-Biological Sciences 281.

1284

Gislason, H. (1999) Single and multispecies reference points for Baltic fish stocks. ICES Journal

1285 of Marine Science 56, 571-583.

1286

1287

1288

1289

1290

1291

1292 1293

1294

1295

1296

1297

1298

1299

1300 1301 331.

Goethel, D.R., Quinn, I., Terrance J, Cadrin, S.X. (2011) Incorporating Spatial Structure in Stock Assessment: Movement Modeling in Marine Fish Population Dynamics. Reviews in Fisheries Science 19, 119-136.

Gottlieb, S.J. (1998) Nutrient removal by age-o Atlantic menhaden (Brevoortia tyrranus) in Chesapeake Bay and implications for seasonal management of the fishery. Ecological Modelling 112, 111-130.

Griffith, G.P., Fulton, E.A. (2014) New approaches to simulating the complex interaction effects of multiple human impacts on the marine environment. ICES Journal of Marine Science 71, 764-774.

Griffith, G.P., Fulton, E.A., Gorton, R., Richardson, A.J. (2012) Predicting Interactions among Fishing, Ocean Warming, and Ocean Acidification in a Marine System with WholeEcosystem Models. Conservation Biology 26, 1145-1 152.

Grimm, V. (1999) Ten years of individual-based modelling in ecology: what have we learned and what could we learn in the future? Ecological Modelling 115, 129-148.

Guisan, A., Thuiller, W. (2005) Predicting species distribution: offering more than simple habitat models. Ecology letters 8, 993-1009. 
1302 Guisan, A., Zimmermann, N.E. (2000) Predictive habitat distribution models in ecology. 1303 Ecological Modelling 135, 147-186.

1304 Hamilton, T.J., Holcombe, A., Tresguerres, M. (2014) CO2-induced ocean acidification 1305

1306 increases anxiety in Rockfish via alteration of $\mathrm{GABA}(\mathrm{A})$ receptor functioning.

Hannah, C., Vezina, A., John, M.S. (2010) The case for marine ecosystem models of Proceedings of the Royal Society B-Biological Sciences 281.

1309

1310

1311

1312

1314

1315

1316

1318

1319

1320

1321

1322 1323 intermediate complexity. Progress in Oceanography 84, 121-128.

Hansen, M.J., Boisclair, D., Brandt, S.B., et al. (1993) Applications of Bioenergetics Models to Fish Ecology and Management: Where Do We Go from Here? Transactions of the American Fisheries Society 122, 1019-1030.

Hare, J.A. (2014) The future of fisheries oceanography lies in the pursuit of multiple hypotheses. ICES Journal of Marine Science 71, 2343-2356.

Hartman, K.J., Kitchell, J.F. (2008) Bioenergetics Modeling: Progress since the 1992 Symposium. Transactions of the American Fisheries Society 137, 216-223.

Hartog, J.R., Hobday, A.J., Matear, R., Feng, M. (2011) Habitat overlap between southern bluefin tuna and yellowfin tuna in the east coast longline fishery - implications for present and future spatial management. Deep Sea Research Part II: Topical Studies in Oceanography 58, 746-752.

Hartvig, M., Andersen, K.H., Beyer, J.E. (2011) Food web framework for size-structured populations. Journal of Theoretical Biology 272, 113-122.

Heath, M.R. (2012) Ecosystem limits to food web fluxes and fisheries yields in the North Sea simulated with an end-to-end food web model. Progress in Oceanography 102, 42-66. 
1324 Heath, M.R., Kunzlik, P.A., Gallego, A., Holmes, S., Wright, P.J. (2008) A model of meta-

1325

1326

1327

1328

1329

1330

1331

1332

1333

1334

1335

1336

1337

1338

1339

1340

1341

1343

1344

1345

1346

1347 population dynamics for North Sea and West of Scotland cod - The dynamic consequences of natal fidelity. Fisheries Research 93, 92-116.

Heikkinen, R.K., Luoto, M., Araujo, M.B., Virkkala, R., Thuiller, W., Sykes, M.T. (2006) Methods and uncertainties in bioclimatic envelope modelling under climate change. Progress in Physical Geography 30, 751-777.

Heisler, N. (1984) Acid-Base Regulation in Fishes. Fish Physiology 10, 315-401.

Hemmer-Hansen, J., Nielsen, E.E., Therkildsen, N.O., et al. (2013) A genomic island linked to ecotype divergence in Atlantic cod. Molecular ecology 22, 2653-2667.

Hemmer-Hansen, J., Therkildsen, N.O., Pujolar, J.M. (2014) Population Genomics of Marine Fishes: Next-Generation Prospects and Challenges. Biological Bulletin 227, 117-132.

Hermann, A.J., Hinckley, S., Megrey, B.A., Napp, J.M. (2001) Applied and theoretical considerations for constructing spatially explicit individual-based models of marine larval fish that include multiple trophic levels. ICES Journal of Marine Science.

Heymans, J.J., Coll, M., Libralato, S., Morissette, L., Christensen, V. (2014) Global Patterns in Ecological Indicators of Marine Food Webs: A Modelling Approach. PloS one $\mathbf{9 .}$

Hidalgo, M., Gusdal, Y., Dingsor, G.E., et al. (2012) A combination of hydrodynamical and statistical modelling reveals non-stationary climate effects on fish larvae distributions. Proceedings of the Royal Society B-Biological Sciences 279, 275-283.

Hilborn, R. (2012) The Evolution of Quantitative Marine Fisheries Management 1985-2010. Natural Resource Modeling 25, 122-144.

Hildebrandt, N., Niehoff, B., Sartoris, F.J. (2014) Long-term effects of elevated CO2 and temperature on the Arctic calanoid copepods Calanus glacialis and C. hyperboreus. Marine pollution bulletin 80, 59-70. 
1348 Hilmi, N., Allemand, D., Dupont, S., et al. (2013) Towards improved socio-economic assessments of ocean acidification's impacts. Marine Biology 160, 1773-1787.

1350 Hinckley, S., Hermann, A.J., Megrey, B.A. (1996) Development of a spatially explicit, individual-based model of marine fish early life history. Marine Ecology Progress Series 139, 47-68.

Hinrichsen, H.H., Dickey-Collas, M., Huret, M., Peck, M.A., Vikebo, F.B. (2011) Evaluating the

Hölker, F., Breckling, B. (2005) A spatiotemporal individual-based fish model to investigate suitability of coupled biophysical models for fishery management. ICES Journal of Marine Science 68, 1478-1487.

Holling, C.S. (1959) The components of predation as revealed by a study of small-mammal predation of the European pine sawfly. The Canadian Entomologist.

1361 1362

1363

1364 1365 emergent properties at the organismal and the population level. Ecological Modelling 186, 406-426.

Hollowed, A.B. (2000) Are multispecies models an improvement on single-species models for measuring fishing impacts on marine ecosystems? ICES Journal of Marine Science 57, $707-719$

Hollowed, A.B., Barange, M., Beamish, R.J., et al. (2013) Projected impacts of climate change on marine fish and fisheries. ICES Journal of Marine Science 70, 1023-1037.

Hollowed, A.B., Bond, N.A., Wilderbuer, T.K., et al. (2009) A framework for modelling fish and shellfish responses to future climate change. ICES Journal of Marine Science 66, 15841594.

Hollowed, A.B., Curchitser, E.N., Stock, C.A., Zhang, C.I. (2012) Trade-offs associated with different modeling approaches for assessment of fish and shellfish responses to climate change. Climatic Change 119, $111-129$. 
1372 Holsman, K.K., Essington, T., Miller, T.J., Koen-Alonso, M., Stockhausen, W.J. (2012) 1373 Comparative analysis of cod and herring production dynamics across 13 northern 1374 hemisphere marine ecosystems. Marine Ecology Progress Series 459, 23 1-246.

1375

1376

Holt, R.E., Jørgensen, C. (2014) Climate warming causes life-history evolution in a model for

1377

1378

1379

1380

1381

1382

1383

1384

1385

1386

1387

1388

1389

1390

1391

1392

1393

1394 Atlantic cod (Gadus morhua). Conservation Physiology 2, 1-16.

Holt, R.E., Jørgensen, C. (2015) Climate change in fish: effects of respiratory constraints on optimal life history and behaviour. Biology letters 11.

Howell, D., Filin, A.A., Bogstad, B., Stiansen, J.E. (2013) Unquantifiable uncertainty in projecting stock response to climate change: Example from North East Arctic cod. Marine Biology Research 9, 920-931.

Huebert, K.B., Peck, M.A. (2014) A Day in the Life of Fish Larvae: Modeling Foraging and Growth Using Quirks. PloS one $\mathbf{9}$.

Hunsicker, M.E., Ciannelli, L., Bailey, K.M., et al. (2011) Functional responses and scaling in predator-prey interactions of marine fishes: contemporary issues and emerging concepts. Ecology letters 14, 1288-1299.

Huse, G., Fiksen, Ø. (2010) Modelling encounter rates and distribution of mobile predators and prey. Progress in Oceanography 84, 93-104.

Huston, M., DeAngelis, D., Post, W. (1988) New Computer Models Unify Ecological Theory. BioScience 38, 682-691.

Inaba, K., Dreanno, C., Cosson, J. (2003) Control of flatfish sperm motility by $\mathrm{CO} 2$ and carbonic anhydrase. Cell Motility and the Cytoskeleton 55, 174-187.

Ito, S., Kishi, M.J., Kurita, Y., et al. (2004) Initial design for a fish bioenergetics model of Pacific saury coupled to a lower trophic ecosystem model. Fisheries Oceanography 13, 111-124. 
1395 Jacobsen, N.S., Gislason, H., Andersen, K.H. (2014) The consequences of balanced harvesting of fish communities. Proceedings of the Royal Society B-Biological Sciences 281.

1397 Janssen, M.A., Bodin, O., Anderies, J.M., et al. (2006) Toward a network perspective of the 1398 study of resilience in social-ecological systems. Ecology and Society 11.

1399 Jennings, S., Brander, K. (2010) Predicting the effects of climate change on marine communities $1400 \quad$ and the consequences for fisheries. Journal of Marine Systems 79, 418-426.

1401 Jones, M.C., Dye, S.R., Pinnegar, J.K., Warren, R., Cheung, W.W. (2014) Using scenarios to 1402 project the changing profitability of fisheries under climate change. Fish and Fisheries.

1403 Jørgensen, C., Enberg, K., Dunlop, E.S., et al. (2007) Managing evolving fish stocks. Science.

1404 Jørgensen, C., Fiksen, Ø. (2006) State-dependent energy allocation in cod (Gadus morhua). 1405 Canadian Journal of Fisheries and Aquatic Sciences 63, 186-199.

1406 Jørgensen, C., Peck, M.A., Antognarelli, F., et al. (2012) Conservation physiology of marine 1407 fishes: advancing the predictive capacity of models. Biology letters 8, 900-903.

1408 Judson, O.P. (1994) The Rise of the Individual-Based Model in Ecology. Trends in Ecology E $1409 \quad$ Evolution 9, 9-14.

1410 Jutfelt, F., Bresolin de Souza, K., Vuylsteke, A., Sturve, J. (2013) Behavioural Disturbances in a $1411 \quad$ Temperate Fish Exposed to Sustained High- $\mathrm{CO}_{2}$ Levels. PloS one 8.

1412 Jutfelt, F., Hedgarde, M. (2013) Atlantic cod actively avoid CO 2 and predator odour, even after 1413 long-term $\mathrm{CO} 2$ exposure. Frontiers in Zoology 10.

1414 Kaplan, I.C., Horne, P.J., Levin, P.S. (2012) Screening California Current fishery management 1415 scenarios using the Atlantis end-to-end ecosystem model. Progress in Oceanography 102, 1416 $5-18$. 
1417 Kaschner, K., Watson, R., Trites, A.W., Pauly, D. (2006) Mapping world-wide distributions of marine mammal species using a relative environmental suitability (RES) model. Marine Ecology Progress Series 316, 285-310.

1420 Kearney, M., Porter, W. (2009) Mechanistic niche modelling: combining physiological and spatial data to predict species' ranges. Ecology letters 12, 334-350.

Kearney, M., Simpson, S.J., Raubenheimer, D., Helmuth, B. (2010) Modelling the ecological niche from functional traits. Philosophical transactions of the Royal Society of London. Series B, Biological sciences 365, 3469-3483.

Keith, D.A., Akcakaya, H.R., Thuiller, W., et al. (2008) Predicting extinction risks under climate change: coupling stochastic population models with dynamic bioclimatic habitat models. Biology letters 4, 560-563.

Kempf, A., Dingsor, G.E., Huse, G., Vinther, M., Floeter, J., Temming, A. (2010) The importance of predator-prey overlap: predicting North Sea cod recovery with a multispecies assessment model. ICES Journal of Marine Science 67, 1989-1997.

1431 Keyl, F., Wolff, M. (2007) Environmental variability and fisheries: what can models do? Reviews in Fish Biology and Fisheries 18, 273-299.

1433 Kitagawa, T., Nakata, H., Kimura, S., Itoh, T., Tsuji, S., Nitta, A. (2000) Effect of ambient 1434 temperature on the vertical distribution and movement of Pacific bluefin tuna Thunnus thynnus orientalis. Marine Ecology Progress Series 206, 25 1-260.

Kjesbu, O.S., Bogstad, B., Devine, J.A., et al. (2014) Synergies between climate and management 1437 for Atlantic cod fisheries at high latitudes. Proceedings of the National Academy of Sciences of the United States of America 11 1, 3478-3483.

1439 Klanjscek, T., Caswell, H., Neubert, M.G., Nisbet, R.M. (2006) Integrating dynamic energy 1440 budgets into matrix population models. Ecological Modelling 196, 407-420. 
1441 Knudby, A., Brenning, A., LeDrew, E. (2010) New approaches to modelling fish-habitat 1442 relationships. Ecological Modelling 22 1, 503-511.

1443 Knutsen, H., Moland Olsen, E., Ciannelli, L., et al. (2007) Egg distribution, bottom topography 1444 and small-scale cod population structure in a coastal marine system. Marine Ecology $1445 \quad$ Progress Series 333, 249-255.

1446 Kooijman, S.A.L.M. (2000) Dynamic energy and mass budgets in biological systems, 2nd edn Vol., 1447 Cambridge University Press, Cambridge, UK ; New York, NY, USA.

1448 Köster, F.W., Hinrichsen, H.-H., St John, M.A., et al. (2001) Developing Baltic cod recruitment 1449 models. II. Incorporation of environmental variability and species interaction. Canadian Journal of Fisheries and Aquatic Sciences 58, 1534-1556.

1451 Kristiansen, T., Drinkwater, K.F., Lough, R.G., Sundby, S. (2011) Recruitment Variability in 1452 North Atlantic Cod and Match-Mismatch Dynamics. PloS one 6, e 17456.

1453 Kristiansen, T., Jorgensen, C., Lough, R.G., Vikebo, F., Fiksen, Ø. (2009) Modeling rule-based 1454 1455 behavior: habitat selection and the growth-survival trade-off in larval cod. Behavioral Ecology 20, 490-500.

1456 Lassalle, G., Bourdaud, P., Saint-Béat, B., Rochette, S., Niquil, N. (2014) A toolbox to evaluate 1457 data reliability for whole-ecosystem models: Application on the Bay of Biscay 1458 continental shelf food-web model. Ecological Modelling 285, 13-2 1.

1459 Law, R. (2000) Fishing, selection, and phenotypic evolution. ICES Journal of Marine Science 57, $1460 \quad 659-668$.

1461 Le Quesne, W.J.F., Pinnegar, J.K. (2012) The potential impacts of ocean acidification: scaling 1462 from physiology to fisheries. Fish and Fisheries 13, 333-344. 
1463 Leduc, A.O.H.C., Munday, P.L., Brown, G.E., Ferrari, M.C.O. (2013) Effects of acidification on 1464 1465 olfactory-mediated behaviour in freshwater and marine ecosystems: a synthesis. Philosophical Transactions of the Royal Society B-Biological Sciences $\mathbf{3 6 8 .}$

1466 Lefort, S., Aumont, O., Bopp, L., Arsouze, T., Gehlen, M., Maury, O. (2015) Spatial and body1467 size dependent response of marine pelagic communities to projected global climate change. Global Change Biology 21, 154-164.

1469

Lehodey, P., Alheit, J., Barange, M., et al. (2006) Climate Variability, Fish, and Fisheries. Journal of Climate 19, 5009-5030.

Lehodey, P., Senina, I., Murtugudde, R. (2008) A spatial ecosystem and populations dynamics model (SEAPODYM) - Modeling of tuna and tuna-like populations. Progress in Oceanography 78, 304-318.

1475

Lehodey, P., Senina, I., Nicol, S., Hampton, J. (2015) Modelling the impact of climate change on South Pacific albacore tuna. Deep-Sea Research Part Ii-Topical Studies in Oceanography 113, 246-259.

Lenoir, S., Beaugrand, G., Lecuyer, É. (2010) Modelled spatial distribution of marine fish and projected modifications in the North Atlantic Ocean. Global Change Biology 17, 115-129.

Lett, C., Ayata, S.-D., Huret, M., Irisson, J.-O. (2010) Biophysical modelling to investigate the effects of climate change on marine population dispersal and connectivity. Progress in Oceanography 87, 106-113.

Lett, C., Verley, P., Mullon, C., et al. (2008) A Lagrangian tool for modelling ichthyoplankton dynamics. Environmental Modelling and Software 23, 1210-1214.

1484 Lewy, P., Vinther, M. (2004) A stochastic age-length-structured multispecies model applied to 1485 North Sea stocks. ICES CM, 33. 
1486 Libralato, S., Solidoro, C. (2009) Bridging biogeochemical and food web models for an End-to-

1487

1488

1489

1490

1491

1492

1493

1494

1495

1496

1497

1498

1499

1500

1501

1502

1503

1504

1505

1506

1507

1508

End representation of marine ecosystem dynamics: The Venice lagoon case study. Ecological Modelling 220, 2960-2971.

Lika, K., Kooijman, S.A.L.M. (2011) The comparative topology of energy allocation in budget models. Journal of Sea Research 66, 381-391.

Lindegren, M., Checkley, D.M. (2013) Temperature dependence of Pacific sardine (Sardinops sagax) recruitment in the California Current Ecosystem revisited and revised. Canadian Journal of Fisheries and Aquatic Sciences 70, 245-252.

Lindstrøm, U., Smout, S., Howell, D., Bogstad, B. (2009) Modelling multi-species interactions in the Barents Sea ecosystem with special emphasis on minke whales and their interactions with cod, herring and capelin. Deep-Sea Research Part II 56, 2068-2079.

Link, J., Overholtz, W., O'Reilly, J., et al. (2008) The Northeast US continental shelf Energy Modeling and Analysis exercise (EMAX): Ecological network model development and basic ecosystem metrics. Journal of Marine Systems 74, 453-474.

Link, J.S. (2010) Adding rigor to ecological network models by evaluating a set of pre-balance diagnostics: A plea for PREBAL. Ecological Modelling 22 1, 1580-1591.

Link, J.S., Bogstad, B., Sparholt, H., Lilly, G.R. (2009) Trophic role of Atlantic cod in the ecosystem. Fish and Fisheries 10, 58-87.

Liquete, C., Piroddi, C., Drakou, E.G., et al. (2013) Current Status and Future Prospects for the Assessment of Marine and Coastal Ecosystem Services: A Systematic Review. PloS one 8, e67737.

Lischka, S., Riebesell, U. (2012) Synergistic effects of ocean acidification and warming on overwintering pteropods in the Arctic. Global Change Biology 18, 3517-3528. 
1509 Livi, C.M., Jordán, F., Lecca, P., Okey, T.A. (2011) Identifying key species in ecosystems with $1510 \quad$ stochastic sensitivity analysis. Ecological Modelling 222, 2542-2551.

1511 Livingston, P. (2000) A multispecies virtual population analysis of the eastern Bering Sea. ICES 1512 Journal of Marine Science 57, 294-299.

1513 Llopiz, J.K., Cowen, R.K., Hauff, M.J., et al. (2014) Early Life History and Fisheries 1514 Oceanography New Questions in a Changing World. Oceanography 27, 26-41.

1515 1516 1517 1518 1519 1520

1521 1522 1523 1524 1525 1526 1527 1528 1529 1530 1531

Logan, C.A., Buckley, B.A. (2015) Transcriptomic responses to environmental temperature in eurythermal and stenothermal fishes. Journal of Experimental Biology 218, 1915-1924.

Lurgi, M., Brook, B.W., Saltré, F., Fordham, D.A. (2014) Modelling range dynamics under global change: which framework and why? Methods in Ecology and Evolution.

Magnússon, K. (1995) An overview of the multispecies VPA - theory and applications. Reviews in Fish Biology and Fisheries 5, 195-212.

Mangel, M., Levin, P.S. (2005) Regime, phase and paradigm shifts: making community ecology the basic science for fisheries. Philosophical transactions of the Royal Society of London. Series B, Biological sciences 360, 95-105.

Mariani, P., Visser, A.W. (2010) Optimization and emergence in marine ecosystem models. Progress in Oceanography 84, 89-92.

Martin, B.T., Jager, T., Nisbet, R.M., Preuss, T.G., Grimm, V. (2013) Predicting Population Dynamics from the Properties of Individuals: A Cross-Level Test of Dynamic Energy Budget Theory. The American Naturalist 181, 506-519.

Martin, B.T., Zimmer, E.I., Grimm, V., Jager, T. (2011) Dynamic Energy Budget theory meets individual-based modelling: a generic and accessible implementation. Methods in Ecology and Evolution 3, 445-449. 
1532 Maury, O. (2010) An overview of APECOSM, a spatialized mass balanced "Apex Predators

1533

1534

1535

1536

1537

1538

1539

1540

1541

1542

1543

1544

1545

1546

1547

1548

1549

1550

1551

1552

1553

1554

1555

ECOSystem Model” to study physiologically structured tuna population dynamics in their ecosystem. Progress in Oceanography 84, 113-117.

Maury, O., Poggiale, J.-C. (2013) From individuals to populations to communities: A dynamic energy budget model of marine ecosystem size-spectrum including life history diversity. Journal of Theoretical Biology 324, 52-7 1.

Megrey, B.a., Rose, K.a., Klumb, R.a., et al. (2007) A bioenergetics-based population dynamics model of Pacific herring (Clupea harengus pallasi) coupled to a lower trophic level nutrient-phytoplankton-zooplankton model: Description, calibration, and sensitivity analysis. Ecological Modelling 202, 144-164.

Melzner, F., Göbel, S., Langenbuch, M., Gutowska, M.A., Pörtner, H.-O., Lucassen, M. (2009a) Swimming performance in Atlantic Cod (Gadus morhua) following long-term (4-12 months) acclimation to elevated seawater PCO2. Aquatic Toxicology 92, 30-37.

Melzner, F., Gutowska, M.A., Langenbuch, M., et al. (2009b) Physiological basis for high $\mathrm{CO}_{2}$ tolerance in marine ectothermic animals: pre-adaptation through lifestyle and ontogeny? Biogeosciences 6, $2313-2331$.

Merino, G., Barange, M., Mullon, C. (2010) Climate variability and change scenarios for a marine commodity: Modelling small pelagic fish, fisheries and fishmeal in a globalized market. Journal of Marine Systems 81, 196-205.

Metcalf, S., Dambacher, J., Hobday, A., Lyle, J. (2008) Importance of trophic information, simplification and aggregation error in ecosystem models. Marine Ecology Progress Series 360, 25-36.

Metcalfe, J.D., Le Quesne, W.J.F., Cheung, W.W.L., Righton, D.a. (2012) Conservation physiology for applied management of marine fish: an overview with perspectives on the 
1556

1557

1558

1559

1560

1561

1562

1563

1564

1565

1566

1567

1568

1569

1570

1571

1572

1573

1574

1575

1576

1577

1578

role and value of telemetry. Philosophical transactions of the Royal Society of London. Series B, Biological sciences 367, 1746-1756.

Michaelidis, B., Spring, A., Pörtner, H.O. (2007) Effects of long-term acclimation to environmental hypercapnia on extracellular acid-base status and metabolic capacity in Mediterranean fish Sparus aurata. Marine Biology 150, 1417-1429.

Miller, G.M., Kroon, F.J., Metcalfe, S., Munday, P.L. (2015) Temperature is the evil twin: effects of increased temperature and ocean acidification on reproduction in a reef fish. Ecological Applications 25, 603-620.

Miller, G.M., Watson, S.A., Donelson, J.M., McCormick, M.I., Munday, P.L. (2012) Parental environment mediates impacts of increased carbon dioxide on a coral reef fish. Nature Climate Change 2, 858-861.

Miller, K., Charles, A., Barange, M., et al. (2010) Climate change, uncertainty, and resilient fisheries: Institutional responses through integrative science. Progress in Oceanography 87, 338-346.

Miller, T.J. (2007) Contribution of individual-based coupled physical-biological models to understanding recruitment in marine fish populations. Marine Ecology Progress Series 347, 127-138.

Mittelbach, G.G., Ballew, N.G., Kjelvik, M.K. (2014) Fish behavioral types and their ecological consequences. Canadian Journal of Fisheries and Aquatic Sciences 71, 927-944.

Moloney, C.L., St John, M.A., Denman, K.L., et al. (2011) Weaving marine food webs from end to end under global change. Journal of Marine Systems 84, 106-1 16.

Monaco, C.J., Helmuth, B. (2011) Tipping points, thresholds and the keystone role of physiology in marine climate change research. Vol. 60. Elsevier, pp. 123-160. 
1579 Mouillot, D., Graham, N.A.J., Villéger, S., Mason, N.W.H., Bellwood, D.R. (2013) A functional 1580

1581 approach reveals community responses to disturbances. Trends in Ecology E Evolution

1582

1583

1584

1585

1586

1587

1588

1589

1590

1591

1592

1593

1594

1595

1596

1597

1598

1599

1600

1601

1602 28, 167-177.

Mullon, C., Cury, P., Penven, P. (2002) Evolutionary individual-based model for the recruitment of anchovy (Engraulis capensis) in the southern Benguela. Canadian Journal of Fisheries and Aquatic Sciences 59, 910-922.

Munday, P.L. (2014) Transgenerational acclimation of fishes to climate change and ocean acidification. F1000Prime Rep 6, 99.

Munday, P.L., Dixson, D.L., Mccormick, M.I., Meekan, M., Ferrari, M.C.O., Chivers, D.P. (2010) Replenishment of fish populations is threatened by ocean acidification. Proceedings of the National Academy of Sciences of the United States of America 107, 1293012934.

Munday, P.L., Pratchett, M.S., Dixson, D.L., et al. (2013a) Elevated CO2 affects the behavior of an ecologically and economically important coral reef fish. Marine Biology 160, 21372144 .

Munday, P.L., Warner, R.R., Monro, K., Pandolfi, J.M., Marshall, D.J. (2013b) Predicting evolutionary responses to climate change in the sea. Ecology letters 16, 1488-1500.

Myers, R.A. (1998) When do environment-recruitment correlations work? Reviews in Fish Biology and Fisheries 8, 285-305.

Nagelkerken, I., Munday, P.L. (2015) Animal behaviour shapes the ecological effects of ocean acidification and warming: moving from individual to community level responses. Global Change Biology, n/a-n/a.

Nagelkerken, I., Russell, B.D., Gillanders, B.M., Connell, S.D. (2015) Ocean acidification alters fish populations indirectly through habitat modification. Nature Clim. Change 6, 89-93. 
1603 Needle, C.L. (2001) Recruitment models: diagnosis and prognosis. Reviews in Fish Biology and 1604 Fisheries 11, 95-111.

1605 Nielsen, E.E., Hemmer-Hansen, J., Larsen, P.F., Bekkevold, D. (2009) Population genomics of 1606 marine fishes: identifying adaptive variation in space and time. Molecular ecology 18, 3128-3150.

1608

Nikinmaa, M. (2013) Climate change and ocean acidification Interactions with aquatic

1609 toxicology. Aquatic Toxicology 126, 365-372.

1610

1611

1612

1613

1614

1615

1616

1617

1618

1619

1620

1621

1622

1623

1624

1625

1626

Nilsson, G.E., Dixson, D.L., Domenici, P., et al. (2012) Near-future carbon dioxide levels alter fish behaviour by interfering with neurotransmitter function. Nature Climate Change 2, 201-204.

Nisbet, R.M., Jusup, M., Klanjscek, T., Pecquerie, L. (2012) Integrating dynamic energy budget (DEB) theory with traditional bioenergetic models. Journal of Experimental Biology 215, 1246-1246.

Nisbet, R.M., Muller, E.B., Lika, K., Kooijman, S.A.L.M. (2000) From molecules to ecosystems through dynamic energy budget models. Journal of Animal Ecology 69, 913-926.

Norman-Lopez, A., Plaganyi, E., Skewes, T., et al. (2013) Linking physiological, population and socio-economic assessments of climate-change impacts on fisheries. Fisheries Research $148,18-26$.

O'Connor, M.I., Bruno, J.F., Gaines, S.D., et al. (2007) Temperature control of larval dispersal and the implications for marine ecology, evolution, and conservation. Proceedings of the National Academy of Sciences 104, 1266-1271.

Oomen, R.A., Hutchings, J.a. (2015) Variation in spawning time promotes genetic variability in population responses to environmental change in a marine fish. Conservation Physiology 3, covO27. 
1627 Österblom, H., Merrie, A., Metian, M., et al. (2013) Modeling Social-Ecological Scenarios in 1628 Marine Systems. BioScience 63, 735-744.

1629 Ottersen, G., Hjermann, D.O., Stenseth, N.C. (2006) Changes in spawning stock structure 1630 strengthen the link between climate and recruitment in a heavily fished cod (Gadus morhua) stock. Fisheries Oceanography 15, 230-243.

1632

Ottersen, G., Stige, L.C., Durant, J.M., et al. (2013) Temporal shifts in recruitment dynamics of

1633

1634 North Atlantic fish stocks: effects of spawning stock and temperature. Marine Ecology

1635

1636

Parmesan, C. (2006) Ecological and Evolutionary Responses to Recent Climate Change. Annual Progress Series 480, 205-225.

1637 Review of Ecology, Evolution, and Systematics 37, 637-669.

1638

Pauly, D. (2010) Gasping fish and panting squids: oxygen, temperature and the growth of water-

1639 breathing animals. Excellence in ecology, Vol. 22, International Ecology Institute, Oldendorf/Luhe, Germany.

1640

Peck, M.A., Hufnagl, M. (2012) Can IBMs tell us why most larvae die in the sea? Model 1641 sensitivities and scenarios reveal research needs. Journal of Marine Systems 93, 77-93.

1642 Pecquerie, L., Petitgas, P., Kooijman, S.A.L.M. (2009) Modeling fish growth and reproduction 1643 in the context of the Dynamic Energy Budget theory to predict environmental impact on anchovy spawning duration. Journal of Sea Research 62, 93-105.

Pecuchet, L., Nielsen, J.R., Christensen, A. (2015) Impacts of the local environment on recruitment: a comparative study of North Sea and Baltic Sea fish stocks. ICES Journal of Marine Science 72, 1323-1335.

1648 Perez-Rodriguez, A., Saborido-Rey, F. (2012) Food consumption of Flemish Cap cod Gadus 1649 morhua and redfish Sebastes sp. using generic bioenergetic models. 1-15. 
1650 Perry, A.L., Low, P.J., Ellis, J.R., Reynolds, J.D. (2005) Climate change and distribution shifts 1651 in marine fishes. Science 308, 1912-1915.

1652 Perry, R.I., Cury, P., Brander, K., Jennings, S., Möllmann, C., Planque, B. (2010) Sensitivity of 1653 marine systems to climate and fishing: Concepts, issues and management responses. $1654 \quad$ Journal of Marine Systems 79, 427-435.

1655 Perry, R.I., Ommer, R.E. (2003) Scale issues in marine ecosystems and human interactions. $1656 \quad$ Fisheries Oceanography 12, 513-522.

1657 Perry, R.I., Ommer, R.E., Barange, M., Jentoft, S., Neis, B., Sumaila, U.R. (2011) Marine social1658 ecological responses to environmental change and the impacts of globalization. Fish and Fisheries 12, 427-450.

1660

1661

Persson, L., Van Leeuwen, A., De Roos, A.M. (2014) The ecological foundation for ecosystem1662 based management of fisheries: mechanistic linkages between the individual-, population-, and community-level dynamics. ICES Journal of Marine Science 71, 2268-

Petitgas, P., Rijnsdorp, A.D., Dickey-Collas, M., et al. (2012) Impacts of climate change on the 2280. complex life cycles of fish. Fisheries Oceanography 22, 1-19.

Petrie, B., Frank, K.T., Shackell, N.L., Leggett, W.C. (2009) Structure and stability in exploited 1668 marine fish communities: quantifying critical transitions. Fisheries Oceanography 18, 83$1668-101$.

1669 Piou, C., Prévost, E. (2012) A demo-genetic individual-based model for Atlantic salmon 1670 populations: Model structure, parameterization and sensitivity. Ecological Modelling

1672 Pistevos, J.C.A., Nagelkerken, I., Rossi, T., Olmos, M., Connell, S.D. (2015) Ocean acidification 1673 and global warming impair shark hunting behaviour and growth. Scientific Reports $\mathbf{5}$. 
1674 Plagányi, É.E. (2007) Models for an ecosystem approach to fisheries. FAO Fisheries Technical 1675 Paper, 1-124.

1676 Plagányi, E.E., Bell, J.D., Bustamante, R.H., et al. (2011) Modelling climate-change effects on 1677 Australian and Pacific aquatic ecosystems: a review of analytical tools and management

1678 implications. Marine and Freshwater Research 62, 1132.

1679 Plagányi, E.E., Ellis, N., Blamey, L.K., et al. (2014a) Ecosystem modelling provides clues to 1680 understanding ecological tipping points. Marine Ecology Progress Series 512, 99-1 13.

1681 Plagányi, E.E., Punt, A.E., Hillary, R., et al. (2014b) Multispecies fisheries management and 1682 conservation: tactical applications using models of intermediate complexity. Fish and

1683 Fisheries 15, 1-22.

1684 Polovina, J.J. (1984) Model of a Coral-Reef Ecosystem. 1. The Ecopath Model and Its 1685 Application to French Frigate Shoals. Coral Reefs 3, 1-11.

1686 Pope, J.G. (1979) A modified cohort analysis in which constant natural mortality is replaced by $1687 \quad$ estimates of predation levels.

1688 Pope, J.G. (1991) The ICES multispecies assessment working group: evolution, insights, and 1689 future problems. ICES Marine Science Symposium.

1690 Pope, J.G., Falk-Pedersen, J., Jennings, S., Rice, J.C., Gislason, H., Daan, N. (2009) Honey, I 1691 cooled the cods: Modelling the effect of temperature on the structure of Boreal/Arctic fish ecosystems. Deep-Sea Research Part Ii-Topical Studies in Oceanography 56, 2097-2 107.

1693 Pope, J.G., Rice, J.C., Daan, N., Jennings, S., Gislason, H. (2006) Modelling an exploited marine 1694 fish community with 15 parameters - results from a simple size-based model. ICES 1695 Journal of Marine Science 63, 1029-1044. 
1696 Pörtner, H.-O. (2010) Oxygen- and capacity-limitation of thermal tolerance: a matrix for

1697

1698

1699

1700

1701

1702

1703

1704

1705

1706

1707

1708

1709

1710

1711

1712

1713

1714

1715

1716

1717 integrating climate-related stressor effects in marine ecosystems. The Journal of experimental biology $\mathbf{2 1 3 , 8 8 1 - 8 9 3 . ~}$

Pörtner, H.O. (2012) Integrating climate-related stressor effects on marine organisms: unifying principles linking molecule to ecosystem-level changes. Marine Ecology Progress Series 470, 273-290.

Pörtner, H.O., Farrell, A.P. (2008) Physiology and Climate Change. Science 322, 690-692.

Pörtner, H.O., Karl, D.M., Boyd, P.W., et al. (2014) Ocean Systems. In: Climate Change 2014: Impacts, Adaptation, and Vulnerability. Part A: Global and Sectoral Aspects. Contribution of Working Group II to the Fifth Assessment Report of the Intergovernmental Panel on Climate Change. (Eds. C.B. Field, V.R. Barros, D.J. Dokken, K.J. Mach, M.D. Mastrandrea, T.E. Bilir, M. Chatterjee, K.L. Ebi, Y.O. Estrada, R.C. Genova, B. Girma, E.S. Kissel, A.N. Levy, S. MacCracken, P.R. Mastrandrea, L.L. White), Cambridge University Press, Cambridge, UK \& New York, USA, pp. 411-484.

Pörtner, H.O., Mark, F.C., Bock, C. (2004) Oxygen limited thermal tolerance in fish?--Answers obtained by nuclear magnetic resonance techniques. Respiratory Physiology $\Xi^{\circ}$ Neurobiology 141, 243-260.

Pörtner, H.O., Peck, M.A. (2010) Climate change effects on fishes and fisheries: towards a cause-and-effect understanding. Journal of fish biology 77, 1745-1779.

Prato, G., Gascuel, D., Valls, A., Francour, P. (2014) Balancing complexity and feasibility in Mediterranean coastal food-web models: uncertainty and constraints. Marine Ecology Progress Series 512, 71-88. 
1718 Queirós, A.M., Fernandes, J.A., Faulwetter, S., et al. (2015) Scaling up experimental ocean

1719

1720

1721

1722

1723

1724

1725

1726

1727

1728

1729

1730

1731

1732

1733

1734

1735

1736

1737

1738

1739

1740 acidification and warming research: from individuals to the ecosystem. Global Change Biology 21, 130-143.

Radtke, H., Neumann, T., Fennel, W. (2013) A Eulerian nutrient to fish model of the Baltic Sea - A feasibility-study. Journal of Marine Systems 125, 61-76.

Railsback, S.F., Lytinen, S.L., Jackson, S.K. (2006) Agent-based simulation platforms: Review and development recommendations. Simulation-Transactions of the Society for Modeling and Simulation International 82, 609-623.

Reusch, T.B.H. (2014) Climate change in the oceans: evolutionary versus phenotypically plastic responses of marine animals and plants. Evolutionary Applications 7, 104-122.

Reuter, H., Hölker, F., Middelhoff, U., Jopp, F., Eschenbach, C., Breckling, B. (2005) The concepts of emergent and collective properties in individual-based models - Summary and outlook of the Bornhoved case studies. Ecological Modelling 186, 489-501.

Reuter, H., Jopp, F., Blanco-Moreno, J.M., Damgaard, C., Matsinos, Y., DeAngelis, D.L. (2010) Ecological hierarchies and self-organisation - Pattern analysis, modelling and process integration across scales. Basic and Applied Ecology 11, 572-581.

Reuter, H., Jopp, F., Holker, F., Eschenbach, C., Middelhoff, U., Breckling, B. (2008) The ecological effect of phenotypic plasticity - Analyzing complex interaction networks (COIN) with agent-based models. Ecological Informatics 3, 35-45.

Ricker, W.E. (1954) Stock and Recruitment. Journal of the Fisheries Research Board of Canada 11, 559-623.

Riebesell, U., Gattuso, J.-p. (2015) Lessons learned from ocean acidification research. Nature Climate Change 5, 12-14. 
1741 Rijnsdorp, A.D., Peck, M.A., Engelhard, G.H., Mollmann, C., Pinnegar, J.K. (2009) Resolving 1742 1743 the effect of climate change on fish populations. ICES Journal of Marine Science 66, 15701583.

1744 Rindorf, A., Lewy, P. (2006) Warm, windy winters drive cod north and homing of spawners 1745 keeps them there. Journal of Applied Ecology 43, 445-453.

1746 Rindorf, A., Schmidt, J., Bogstad, B., Reeves, S., Walther, Y. (2013) A Framework for 1747 Multispecies Assessment and Management. An ICES/NCM Background Document.

1748 Robinson, L.M., Elith, J., Hobday, A.J., et al. (2011) Pushing the limits in marine species 1749 distribution modelling: lessons from the land present challenges and opportunities. Global Ecology and Biogeography 20, 789-802.

1751 Roessig, J.M., Woodley, C.M., Cech, J., Joseph J, Hansen, L.J. (2005) Effects of global climate 1752 change on marine and estuarine fishes and fisheries. Reviews in Fish Biology and Fisheries 1753 $14,251-275$.

1754 Rose, G.A. (2004) Reconciling overfishing and climate change with stock dynamics of Atlantic 1755 cod (Gadus morhua) over 500 years. Can. J. Fish. Aquat. Sci. 61, 1553-1557.

1756 Rose, G.A. (2005) On distributional responses of North Atlantic fish to climate change. ICES Journal of Marine Science 62, 1360-1374.

1758 Rose, K.A. (2012) End-to-end models for marine ecosystems: Are we on the precipice of a 1759 significant advance or just putting lipstick on a pig? Scientia Marina 76, 195-201.

1760 Rose, K.A., Allen, J.I., Artioli, Y., et al. (2010) End-To-End Models for the Analysis of Marine 1761 Ecosystems: Challenges, Issues, and Next Steps. Marine and Coastal Fisheries 2, 115-130.

1762 Rose, K.A., Cowan, J., James H, Winemiller, K.O., Myers, R.A., Hilborn, R. (2001) 1763 Compensatory density dependence in fish populations: importance, controversy, $1764 \quad$ understanding and prognosis. Fish and Fisheries 2, 293-327. 
1765 Rose, K.A., Fiechter, J., Curchitser, E.N., et al. (2015) Demonstration of a fully-coupled end-to-

1766

1767

1768

1769

1770

1771

1772

1773

1774

1775

1776

1777

1778

1779

1780

1781

1782

1783

1784

1785

1786

1787 end model for small pelagic fish using sardine and anchovy in the California Current. Progress in Oceanography 138, 348-380.

Rose, K.A., Megrey, B.A., Hay, D., Werner, F., Schweigert, J. (2008) Climate regime effects on Pacific herring growth using coupled nutrient-phytoplankton-zooplankton and bioenergetics models. Transactions of the American Fisheries Society 137, 278-297.

Rose, K.A., Sable, S.E. (2009) Multispecies modeling of fish populations. In: Computers in fisheries research. Springer, pp. 373-397.

Rossoll, D., Bermudez, R., Hauss, H., et al. (2012) Ocean Acidification-Induced Food Quality Deterioration Constrains Trophic Transfer. PloS one 7.

Rothschild, B.J., Osborn, T.R., Dickey, T.D., Farmer, D.M. (1989) The Physical Basis for Recruitment Variability in Fish Populations. Journal Du Conseil 45, 136-145.

Rummer, J.L., Stecyk, J.A.W., Couturier, C.S., Watson, S.-A., Nilsson, G.E., Munday, P.L. (2013) Elevated $\mathrm{CO} 2$ enhances aerobic scope of a coral reef fish. Conservation Physiology $1,1-7$.

Runge, J.A., Kovach, A.I., Churchill, J.H., et al. (2010) Understanding climate impacts on recruitment and spatial dynamics of Atlantic cod in the Gulf of Maine: Integration of observations and modeling. Progress in Oceanography 87, 251-263.

Russell, B.D., Harley, C.D.G., Wernberg, T., et al. (2012) Predicting ecosystem shifts requires new approaches that integrate the effects of climate change across entire systems. Biology letters 8, 164-166.

Ruth, M., Lindholm, J. (1996) Dynamic modelling of multispecies fisheries for consensus building and management. Environmental Conservation 23, 332-342. 
1788 Scheffer, M., Baveco, J.M., DeAngelis, D.L., Rose, K.A., van Nes, E.H. (1995) Super-individuals 1789

1790 a simple solution for modelling large populations on an individual basis. Ecological Modelling 80, 161-170.

1791 Schlüter, M., Mcallister, R.R.J., Arlinghaus, R., et al. (2012) New Horizons for Managing the 1792 Environment: A Review of Coupled Social-Ecological Systems Modeling. Natural 1793 Resource Modeling 25, 219-272.

1794 Scott, F., Blanchard, J.L., Andersen, K.H. (2014) mizer: an R package for multispecies, trait1795 based and community size spectrum ecological modelling. Methods in Ecology and 1796 Evolution 5, 1121-1125.

1797 Shama, L.N.S., Strobel, A., Mark, F.C., Wegner, K.M. (2014) Transgenerational plasticity in 1798

1799 marine sticklebacks: maternal effects mediate impacts of a warming ocean. Functional Ecology 28, 1482-1493.

1800

1801

Shannon, L., Coll, M., Bundy, A., et al. (2014) Trophic level-based indicators to track fishing impacts across marine ecosystems. Marine Ecology Progress Series 512, 115-140.

1802

1803

1804

Shannon, L.J., Christensen, V., Walters, C.J. (2004) Modelling stock dynamics in the southern Benguela ecosystem for the period 1978-2002. African Journal of Marine Science 26, 179196.

1805 Shin, Y.-J., Travers, M., Maury, O. (2010) Coupling low and high trophic levels models: 1806 1807 Towards a pathways-orientated approach for end-to-end models. Progress in Oceanography 84, 105-112.

1808 Shin, Y.J., Cury, P. (2001) Exploring fish community dynamics through size-dependent trophic 1809 interactions using a spatialized individual-based model. Aquatic Living Resources 14, 6580. 
1811 Shin, Y.J., Cury, P. (2004) Using an individual-based model of fish assemblages to study the

1812

1813

1814

1815

1816

1817

1818

1819

1820

1821

1822

1823

1824

1825

1826

1827

1828

1829

1830

1831

1832 response of size spectra to changes in fishing. Canadian Journal of Fisheries and Aquatic Sciences 61, 414-431.

Sibly, R.M., Grimm, V., Martin, B.T., et al. (2013) Representing the acquisition and use of energy by individuals in agent-based models of animal populations. Methods in Ecology and Evolution 4, 151-161.

Simpson, S.D., Munday, P.L., Wittenrich, M.L., et al. (2011) Ocean acidification erodes crucial auditory behaviour in a marine fish. Biology letters 7, 917-920.

Somero, G.N. (2010) The physiology of climate change: how potentials for acclimatization and genetic adaptation will determine 'winners' and 'losers'. The Journal of experimental biology $213,912-920$.

Sousa, T., Domingos, T., Kooijman, S.A.L.M. (2008) From empirical patterns to theory: a formal metabolic theory of life. Philosophical transactions of the Royal Society of London. Series B, Biological sciences 363, 2453-2464.

Speirs, D.C., Guirey, E.J., Gurney, W.S.C., Heath, M.R. (2010) A length-structured partial ecosystem model for cod in the North Sea. Fisheries Research 106, 474-494.

Steenbeek, J., Coll, M., Gurney, L., et al. (2013) Bridging the gap between ecosystem modeling tools and geographic information systems: Driving a food web model with external spatial-temporal data. Ecological Modelling 263, 139-151.

Stefansson, G. (2003) Issues in Multispecies Models. Natural Resource Modeling 16, 1-23.

Stensholt, B. (2001) Cod migration patterns in relation to temperature: analysis of storage tag data. ICES Journal of Marine Science 58, 770-793. 
1833 Stewart, R.I.A., Dossena, M., Bohan, D.A., et al. (2013) Mesocosm Experiments as a Tool for

1834

1835

1836

1837

1838

1839

1840

1841

1842

1843

1844

1845

1846

1847

1848

1849

1850

1851

1852

1853

1854 Takasuka, A., Oozeki, Y., Aoki, I. (2007) Optimal growth temperature hypothesis: Why do 1855

1856 Ecological Climate-Change Research. Advances in Ecological Research, Vol 48: Global Change in Multispecies Systems, Pt 3 48, 71-181.

Stock, C.A., Alexander, M.A., Bond, N.A., et al. (2011) On the use of IPCC-class models to assess the impact of climate on Living Marine Resources. Progress in Oceanography 88, 127.

Stramma, L., Schmidtko, S., Levin, L.A., Johnson, G.C. (2010) Ocean oxygen minima expansions and their biological impacts. Deep-Sea Research Part I-Oceanographic Research Papers 57, 587-595.

Strobel, A., Bennecke, S., Leo, E., Mintenbeck, K., Portner, H.O., Mark, F.C. (2012) Metabolic shifts in the Antarctic fish Notothenia rossii in response to rising temperature and PCO2. Frontiers in Zoology $\mathbf{9}, 28$.

Strobel, A., Leo, E., Pörtner, H.O., Mark, F.C. (2013) Elevated temperature and PCO2 shift metabolic pathways in differentially oxidative tissues of Notothenia rossii. Comparative Biochemistry and Physiology Part B: Biochemistry and Molecular Biology 166, 48-57.

Sumaila, U.R., Cheung, W.W.L., Lam, V.W.Y., Pauly, D., Herrick, S. (2011) Climate change impacts on the biophysics and economics of world fisheries. Nature Climate Change 1, 449-456.

Szuwalski, C.S., Vert Pre, K.A., Punt, A.E., Branch, T.A., Hilborn, R. (2014) Examining common assumptions about recruitment: a meta analysis of recruitment dynamics for worldwide marine fisheries. Fish and Fisheries 16, 633-648. anchovy flourish and sardine collapse or vice versa under the same ocean regime? Canadian Journal of Fisheries and Aquatic Sciences 64, 768-776. 
1857 Teal, L.R., Marras, S., Peck, M.A., Domenici, P. (2015) Physiology-based modelling approaches 1858 to characterize fish habitat suitability: Their usefulness and limitations. Estuarine, 1859 Coastal and Shelf Science 2015.

1860 Teal, L.R., van Hal, R., van Kooten, T., Ruardij, P., Rijnsdorp, A.D. (2012) Bio-energetics 1861

1862 underpins the spatial response of North Sea plaice ( Pleuronectes platessa L.) and sole ( Solea solea L.) to climate change. Global Change Biology 18, 3291-3305.

1863 Thuiller, W., Lafourcade, B., Engler, R., Araujo, M.B. (2009) BIOMOD - a platform for 1864 ensemble forecasting of species distributions. Ecography 32, 369-373.

1865 Tian, Y., Akamine, T., Suda, M. (2004) Modeling the influence of oceanic-climatic changes on 1866

1867 the dynamics of Pacific saury in the northwestern Pacific using a life cycle model. Fisheries Oceanography 13, 125-137.

Tjelmeland, S., Bogstad, B. (1998) MULTSPEC - a review of a multispecies modelling project 1869 for the Barents Sea. Fisheries Research 37, 127-142.

1870 Travers, M., Shin, Y.J., Jennings, S., Cury, P. (2007) Towards end-to-end models for 1871 investigating the effects of climate and fishing in marine ecosystems. Progress in 1872 Oceanography 75, 751-770.

1873 Travers, M., Shin, Y.J., Jennings, S., et al. (2009) Two-way coupling versus one-way forcing of 1874 plankton and fish models to predict ecosystem changes in the Benguela. Ecological 1875 Modelling 220, 3089-3099.

1876 Travers-Trolet, M., Shin, Y.-J., Shannon, L.J., Moloney, C.L., Field, J.G. (2014) Combined 1877 Fishing and Climate Forcing in the Southern Benguela Upwelling Ecosystem: An End1878 to-End Modelling Approach Reveals Dampened Effects. PloS one 9, e94286.

1879 Ulanowicz, R.E. (1985) Growth and Development: Ecosystems Phenomenology. Springer. 
1880 Ulanowicz, R.E. (2004) Quantitative methods for ecological network analysis. Computational 1881 Biology and Chemistry 28, 321-339.

1882 van der Meer, J. (2006) An introduction to Dynamic Energy Budget (DEB) models with special 1883 emphasis on parameter estimation. Journal of Sea Research 56, 85-102.

1884 van der Veer, H.W., Kooijman, S.A.L.M., van der Meer, J. (2001) Intra- and interspecies 1885 comparison of energy flow in North Atlantic flatfish species by means of dynamic 1886 energy budgets. Journal of Sea Research 45, 303-320.

1887 Van Winkle, W., Rose, K.A., Chambers, R.C. (1993) Individual-Based Approach to Fish 1888 Population Dynamics: An Overview. Transactions of the American Fisheries Society 122, 1889 397-403.

1890 Vikebo, F., Jorgensen, C., Kristiansen, T., Fiksen, Ø. (2007) Drift, growth, and survival of larval 1891 Northeast Arctic cod with simple rules of behaviour. Marine Ecology Progress Series 347, 1892 207-219.

1893 Vikebo, F.B., Husebo, A., Slotte, A., Stenevik, E.K., Lien, V.S. (2010) Effect of hatching date, 1894 1895 1896 vertical distribution, and interannual variation in physical forcing on northward displacement and temperature conditions of Norwegian spring-spawning herring larvae. ICES Journal of Marine Science 67, 1948-1956.

1899

Voinov, A., Shugart, H.H. (2013) 'Integronsters', integral and integrated modeling. Environmental Modelling and Software 39, 149-158.

1900

Voss, R., Hinrichsen, H.H., Quaas, M.F., Schmidt, J.O., Tahvonen, O. (2011) Temperature 1901 change and Baltic sprat: from observations to ecological-economic modelling. ICES Journal of Marine Science 68, 1244-1256. 
1902 Walters, C., Christensen, V., Walters, W., Rose, K. (2010) Representation of multistanza life 1903

1904 histories in Ecospace models for spatial organization of ecosystem trophic interaction patterns. Bulletin of Marine Science 86, 439-459.

1905 Walters, C., Pauly, D., Christensen, V. (1999) Ecospace: Prediction of mesoscale spatial 1906

1907 patterns in trophic relationships of exploited ecosystems, with emphasis on the impacts of marine protected areas. Ecosystems 2, 539-554.

1908

Watson, J.R., Stock, C.A., Sarmiento, J.L. (2014) Exploring the role of movement in 1909

1910 determining the global distribution of marine biomass using a coupled hydrodynamicSize-based ecosystem model. Progress in Oceanography.

1911 Wayte, S.E. (2013) Management implications of including a climate-induced recruitment shift 1912 in the stock assessment for jackass morwong (Nemadactylus macropterus) in southeastern Australia. Fisheries Research 142, 47-55.

1914 Whitehead, A. (2012) Comparative genomics in ecological physiology: toward a more nuanced 1915 understanding of acclimation and adaptation. The Journal of Experimental Biology 215, 884-891.

1917 Wiedmann, M.A., Aschan, M., Certain, G., et al. (2014) Functional diversity of the Barents Sea 1918

1919 Woodin, S.A., Hilbish, T.J., Helmuth, B., Jones, S.J., Wethey, D.S. (2013) Climate change, 1920 species distribution models, and physiological performance metrics: predicting when biogeographic models are likely to fail. Ecology and Evolution 3, 3334-3346.

1922 Woodworth-Jefcoats, P.A., Polovina, J.J., Dunne, J.P., Blanchard, J.L. (2013) Ecosystem size 1923 structure response to 21 st century climate projection: large fish abundance decreases in 1924 the central North Pacific and increases in the California Current. Global Change Biology 1925 19, 724-733. 
1926 Young, J.W., Hunt, B.P.V., Cook, T.R., et al. (2015) The trophodynamics of marine top 1927 predators: Current knowledge, recent advances and challenges. Deep-Sea Research Part Ii-Topical Studies in Oceanography 113, 170-187.

1929 Zimmermann, F., Jorgensen, C. (2015) Bioeconomic consequences of fishing-induced evolution: 1930 a model predicts limited impact on net present value. Canadian Journal of Fisheries and 1931 Aquatic Sciences 72, 612-624.

1932 
Table 1: Overview on model classes for marine fish and their potential for representation of physiological processes and integration of experimental results on various levels of biological organisation. Processes marked by an asterisk* are either incorporated on an aggregate level or non-dynamically (state-independent). Processes in brackets () can only be incorporated in a subset of models of the class or by using additional software features (see text for details). Coupled and end-to-end models can in principle incorporate all processes, and their specific capabilities depend on the model classes they are based on.

\begin{tabular}{|c|c|c|c|c|c|}
\hline \multirow[t]{2}{*}{$\begin{array}{l}\text { model } \\
\text { class }\end{array}$} & \multicolumn{4}{|c|}{ incorporated processes on level of description } & $\begin{array}{c}\text { main use in } \\
\text { climate } \\
\text { change } \\
\text { context }\end{array}$ \\
\hline & Organism & Population & Community & Ecosystem & \\
\hline $\begin{array}{l}\text { 1. Single- } \\
\text { species } \\
\text { population } \\
\text { dynamic }\end{array}$ & $\begin{array}{c}\text { growth* } \\
\text { mortality* } \\
\text { (development*) }\end{array}$ & $\begin{array}{l}\text { recruitment } \\
\text { (reproduction) }\end{array}$ & 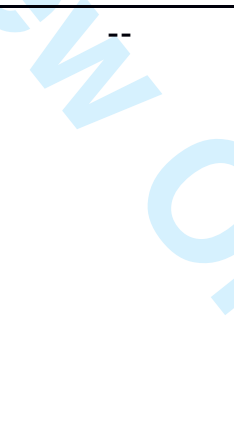 & $\begin{array}{l}\text { migration* } \\
\text { dispersal* }\end{array}$ & $\begin{array}{c}\text { stock } \\
\text { management } \\
\text { (no relevant } \\
\text { stock } \\
\text { interactions) }\end{array}$ \\
\hline $\begin{array}{l}\text { 2. Multi- } \\
\text { species } \\
\text { population } \\
\text { dynamic }\end{array}$ & $\begin{array}{c}\text { growth* } \\
\text { mortality* } \\
\text { (development*) } \\
\text { (foraging*) } \\
\text { (assimilation*) }\end{array}$ & $\begin{array}{l}\text { recruitment } \\
\text { (reproduction) }\end{array}$ & $\begin{array}{l}\text { predation* } \\
\text { competition* }\end{array}$ & $\begin{array}{l}\text { migration* } \\
\text { dispersal* }\end{array}$ & $\begin{array}{c}\text { stock } \\
\text { management } \\
\text { (interactions } \\
\text { important), } \\
\text { community } \\
\text { dynamics }\end{array}$ \\
\hline
\end{tabular}




\begin{tabular}{|c|c|c|c|c|c|}
\hline $\begin{array}{l}\text { 3. tropho- } \\
\text { dynamic \& } \\
\text { mass- } \\
\text { balance }\end{array}$ & $\begin{array}{c}\text { growth* } \\
\text { mortality* } \\
\text { (development*) } \\
\text { foraging* } \\
\text { assimilation* }\end{array}$ & $\begin{array}{l}\text { (recruitment) } \\
\text { (reproduction*) }\end{array}$ & $\begin{array}{l}\text { predation* } \\
\text { competition* } \\
\text { mutualism* }\end{array}$ & $\begin{array}{l}\text { migration } \\
\text { (dispersal) } \\
\text { habitat } \\
\text { (all in } \\
\text { Ecospace) }\end{array}$ & $\begin{array}{l}\text { community } \\
\text { and } \\
\text { ecosystem } \\
\text { resilience, } \\
\text { ecosystem- } \\
\text { based } \\
\text { management }\end{array}$ \\
\hline $\begin{array}{l}\text { 4. species } \\
\text { distri- } \\
\text { bution } \\
\text { (SDM) }\end{array}$ & $\begin{array}{l}\text { growth* } \\
\text { mortality* } \\
\text { foraging* } \\
\text { limitations* }\end{array}$ & recruitment* & $\begin{array}{c}\text { (predation*) } \\
\text { (competition) } \\
\text { (with size } \\
\text { spectrum or } \\
\text { trophic } \\
\text { models) }\end{array}$ & $\begin{array}{c}\text { migration* } \\
\text { (dispersal*) } \\
\text { habitat }\end{array}$ & $\begin{array}{c}\text { distribution } \\
\text { range shifts, } \\
\text { local fish } \\
\text { catch } \\
\text { potential }\end{array}$ \\
\hline $\begin{array}{l}\text { 5. trait- } \\
\text { based \& } \\
\text { size- } \\
\text { spectrum }\end{array}$ & $\begin{array}{c}\text { (plasticity) } \\
\text { behaviour } \\
\text { growth } \\
\text { mortality } \\
\text { development } \\
\text { foraging } \\
\text { assimilation } \\
\text { (metabolism) } \\
\text { energy allocation } \\
\text { limitations }\end{array}$ & $\begin{array}{l}\text { recruitment* } \\
\text { reproduction } \\
\text { adaptation }\end{array}$ & $\begin{array}{l}\text { predation* } \\
\text { competition* }\end{array}$ & habitat* & $\begin{array}{l}\text { trade-offs in } \\
\text { organismal } \\
\text { processes, } \\
\text { adaptation } \\
\text { and } \\
\text { community } \\
\text { structure }\end{array}$ \\
\hline
\end{tabular}




\begin{tabular}{|c|c|c|c|c|c|}
\hline $\begin{array}{l}\text { 6. indi- } \\
\text { vidual- } \\
\text { based } \\
\text { (IBM) }\end{array}$ & $\begin{array}{c}\text { (plasticity) } \\
\text { behaviour } \\
\text { growth } \\
\text { mortality } \\
\text { development } \\
\text { foraging } \\
\text { assimilation } \\
\text { (metabolism) } \\
\text { energy allocation } \\
\text { limitations }\end{array}$ & $\begin{array}{l}\text { recruitment* } \\
\text { reproduction } \\
\text { adaptation }\end{array}$ & $\begin{array}{l}\text { predation } \\
\text { competition } \\
\text { mutualism* }\end{array}$ & $\begin{array}{l}\text { migration } \\
\text { dispersal } \\
\text { habitat }\end{array}$ & $\begin{array}{l}\text { larval } \\
\text { dispersal, } \\
\text { behavioural } \\
\text { and } \\
\text { population } \\
\text { adaptation }\end{array}$ \\
\hline $\begin{array}{c}\text { 7. bio- } \\
\text { energetic }\end{array}$ & $\begin{array}{c}\text { growth } \\
\text { mortality } \\
\text { (development) } \\
\text { foraging } \\
\text { assimilation } \\
\text { metabolism } \\
\text { energy allocation } \\
\text { (limitations) }\end{array}$ & $\begin{array}{l}\text { (recruitment) } \\
\text { (reproduction) } \\
\text { (in IBMs) }\end{array}$ & $\begin{array}{l}\text { (predation) } \\
\text { (competition) } \\
\text { (in size- } \\
\text { spectrum } \\
\text { models) }\end{array}$ & $\begin{array}{c}\text { (migration) } \\
\text { (habitat) } \\
\text { (in IBMs or } \\
\text { SDMs) }\end{array}$ & $\begin{array}{l}\text { trade-offs in } \\
\text { organismal } \\
\text { processes, } \\
\text { linking of } \\
\text { individual } \\
\text { effects to } \\
\text { community } \\
\text { dynamics }\end{array}$ \\
\hline $\begin{array}{l}\text { 8. coupled } \\
\text { \& end-to- } \\
\text { end }\end{array}$ & $\begin{array}{l}\text { [based on multi- } \\
\text { species, size- } \\
\text { spectrum, IBM, } \\
\text { or bioenergetic] }\end{array}$ & $\begin{array}{l}\text { recruitment* } \\
\text { reproduction } \\
\text { adaptation }\end{array}$ & $\begin{array}{c}\text { predation } \\
\text { competition } \\
\text { mutualism* }\end{array}$ & $\begin{array}{l}\text { migration } \\
\text { dispersal } \\
\text { habitat }\end{array}$ & $\begin{array}{l}\text { ecosystem- } \\
\text { based } \\
\text { management, } \\
\text { distribution } \\
\text { and regime } \\
\text { shifts }\end{array}$ \\
\hline
\end{tabular}


1934

1935 Figure 1: Overview over physiological and ecological processes, as a framework to assess 1936 potential effects of environmental drivers on fish stocks. Processes are separated among 1937 different levels of biological hierarchy, from organism and suborganismal (cell and tissue 1938 or organ) processes to population, community, and spatio-temporal ecosystem processes.

1939 Environmental drivers such as warming, acidification, hypoxia and others (bottom) act

1940 directly on organisms and indirectly affect processes on higher levels, shaping the

1941 characteristics resulting at each level of description (right). Higher-level processes are

1942 aggregate descriptions of processes on lower levels, and this framework is proposed to

1943 represent an easily observable and quantifiable description, but alternative descriptions

1944 are possible (e.g., recruitment can be described as the product of growth, foraging and

1945 mortality of early life stages, and evolution is the product of individual plasticity,

1946 acclimation and adaptations, and population adaptation). For details on processes and 1947 effects, see section two. 


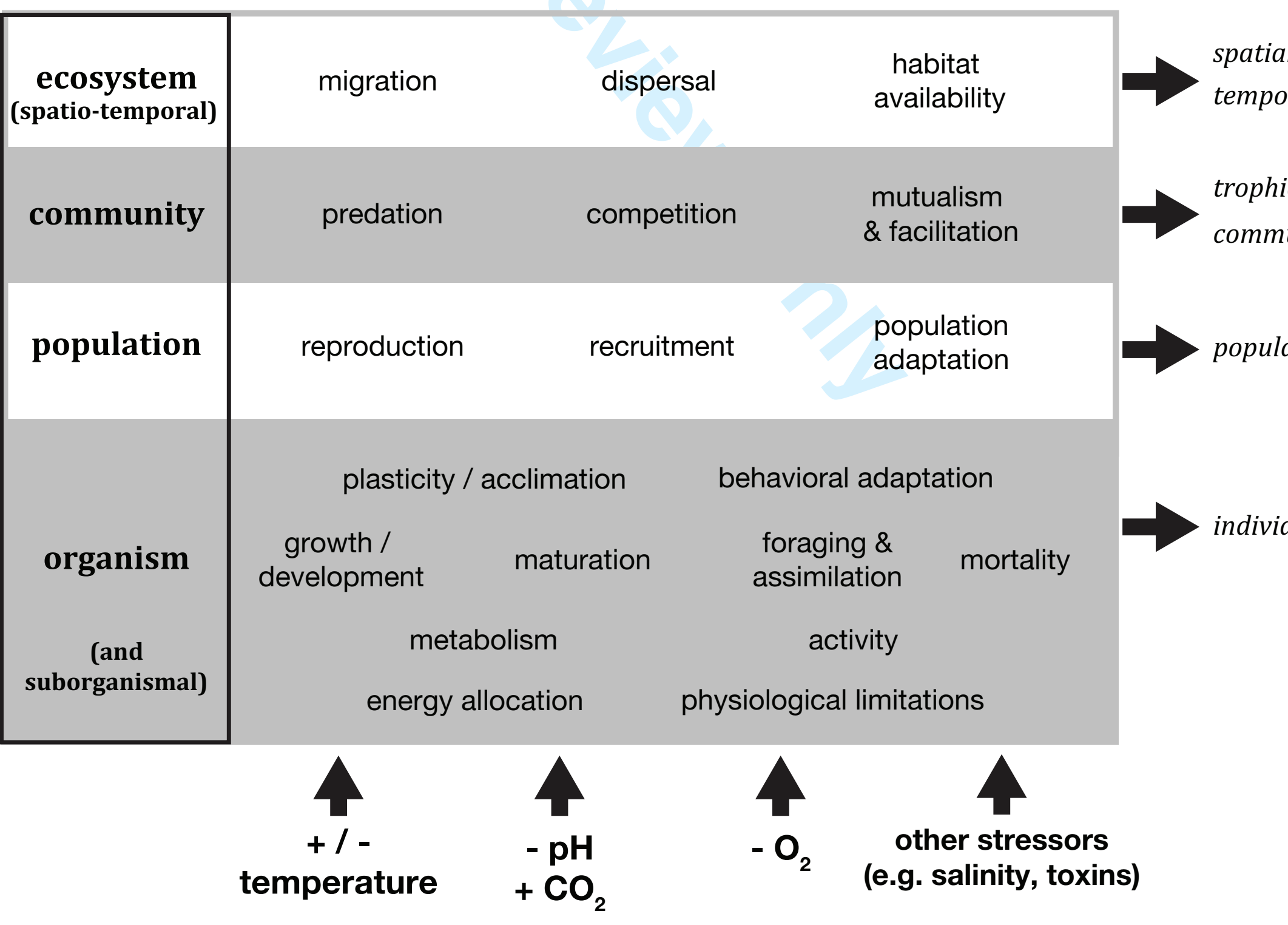

